\title{
Association of mutations in the Plasmodium falciparum Kelch13 gene (Pf3D7_1343700) with parasite clearance rates after artemisinin-based treatments-a WWARN individual patient data meta-analysis
}

WWARN K13 Genotype-Phenotype Study Group

\begin{abstract}
Background: Plasmodium falciparum infections with slow parasite clearance following artemisinin-based therapies are widespread in the Greater Mekong Subregion. A molecular marker of the slow clearance phenotype has been identified: single genetic changes within the propeller region of the Kelch13 protein (pfk13; Pf3D7_1343700). Global searches have identified almost 200 different non-synonymous mutant pfk 13 genotypes. Most mutations occur at low prevalence and have uncertain functional significance. To characterize the impact of different pfk 13 mutations on parasite clearance, we conducted an individual patient data meta-analysis of the associations between parasite clearance half-life $\left(\mathrm{PC}_{1 / 2}\right)$ and pfk13 genotype based on a large set of individual patient records from Asia and Africa.
\end{abstract}

Methods: A systematic literature review following the PRISMA protocol was conducted to identify studies published between 2000 and 2017 which included frequent parasite counts and pfk13 genotyping. Four databases (Ovid Medline, PubMed, Ovid Embase, and Web of Science Core Collection) were searched. Eighteen studies (15 from Asia, 2 from Africa, and one multicenter study with sites on both continents) met inclusion criteria and were shared. Associations between the log transformed $\mathrm{PC}_{1 / 2}$ values and pfk 13 genotype were assessed using multivariable regression models with random effects for study site.

Results: Both the pfk 13 genotypes and the $\mathrm{PC}_{1 / 2}$ were available from 3250 (95\%) patients ( $n=3012$ from Asia (93\%), $n=238$ from Africa (7\%)). Among Asian isolates, all pfk 13 propeller region mutant alleles observed in five or more specific isolates were associated with a 1.5- to 2.7-fold longer geometric mean $\mathrm{PC}_{1 / 2}$ compared to the $\mathrm{PC}_{1 / 2}$ of wild type isolates (all $p \leq 0.002$ ). In addition, mutant allele E252Q located in the $P$. falciparum region of $p f k 13$ was associated with 1.5-fold $(95 \% \mathrm{Cl} 1.4-1.6)$ longer $\mathrm{PC}_{1 / 2}$. None of the isolates from four countries in Africa showed a significant difference between the $\mathrm{PC}_{1 / 2}$ of parasites with or without $p f k 13$ propeller region mutations.

Previously, the association of six pfk 13 propeller mutant alleles with delayed parasite clearance had been confirmed. This analysis demonstrates that 15 additional pfk 13 alleles are associated strongly with the slow-clearing phenotype in Southeast Asia.

Conclusion: Pooled analysis associated 20 pfk 13 propeller region mutant alleles with the slow clearance phenotype, including 15 mutations not confirmed previously.

(c) The Author(s). 2019 Open Access This article is distributed under the terms of the Creative Commons Attribution 4.0 International License (http://creativecommons.org/licenses/by/4.0/), which permits unrestricted use, distribution, and reproduction in any medium, provided you give appropriate credit to the original author(s) and the source, provide a link to the Creative Commons license, and indicate if changes were made. The Creative Commons Public Domain Dedication waiver (http://creativecommons.org/publicdomain/zero/1.0/) applies to the data made available in this article, unless otherwise stated. 


\section{Background}

Artemisinin-based combination therapies (ACTs) have been the WHO recommended treatment for uncomplicated Plasmodium falciparum malaria since 2006. Studies conducted in 2006-2007 reported that P. falciparum parasites in northwest Cambodia had reduced in vivo susceptibility to artemisinins $[1,2]$. This was manifest as delayed clearance of parasites from the blood of patients treated with artesunate monotherapy or ACTs [2]. In 2014, parasites selected in vitro for delayed response to artemisinins were found to have a mutation in the kelch13 gene (pfk13, P. falciparum 3D7_1343700) [3, 4], a locus consistent with genome association studies that had strongly associated a region of chromosome 13 with slow parasite clearance $[5,6]$. Subsequent clinical studies in western Cambodia showed that delayed parasite clearance in clinical trials was associated with several nonsynonymous mutations in $p f k 13$. In particular, mutations in the distinctive propeller region of the Kelch 13 protein (codons 441-726) were associated with slow parasite clearance and subsequently with reduced artemisinin susceptibility in in vitro studies assessing susceptibility of the ring-stage parasites [3, 7, 8]. Recently, the structure of the propeller region was solved and made public by the Structural Genetics Consortium [9], making it possible to link particular genetic changes with their position in the molecule. A central role of $p f k 13$ propeller mutations in mediating ring-stage resistance was confirmed by demonstration that parasites engineered to contain the mutations showed ring-stage resistance to artemisinin whereas parasites with the wild type allele were sensitive [10].

As pfk 13 propeller sequences were determined in P. falciparum from the Greater Mekong Subregion (GMS), other Asian sites [6, 11-22], and Africa, Latin America, and Oceania [23-26]; almost 200 different non-synonymous mutations have been identified (see [27] and supplementary tables 6 and 7 in [28]).

The parasite clearance half-life $\left(\mathrm{PC}_{1 / 2}\right)$, which measures the slope of the log-linear component of the parasite clearance curve, has become established as the best in vivo metric of $P$. falciparum artemisinin susceptibility [29-31]. Although sporadic parasite isolates with $p f k 13$ propeller mutations and occasional patients with slow parasite clearance have been identified in many parts of the malaria-endemic world, pfk13 mutant parasites isolated from patients with the slow-clearing in vivo phenotype have been demonstrated only in a circumscribed region of Southeast Asia, initially in western Cambodia and currently extending to parts of Thailand, Vietnam, Lao PDR, Myanmar, and Yunnan Province, China. Within this region, there has been clear evidence of selection and spread of successful artemisinin-resistant parasite lineages [32]. As expected, artemisinin resistance has led to further selection of ACT partner drug resistance [33-35]. Outside the GMS, extensive molecular analyses have shown no evidence that parasites carrying $p f k 13$ propeller SNPs are under directional selection by artemisinins [23, 25, 27, 28, 36]. Taken together, available studies generally support the conclusion that certain $p f k 13$ propeller mutations mediate delayed parasite clearance following treatment with artemisinin derivatives in Southeast Asia, but that the $p f k 13$ propeller region mutants observed outside the GMS do not show an association with slow parasite clearance [37, 38]. Exceptions include recent molecular reports of independent emergence of parasites that carry pfk 13 propeller mutant alleles observed previously in the GMS in Guyana (C580Y) [39] and Rwanda (P574L and $\mathrm{A} 675 \mathrm{~V}$ ) [40]. Accurate measurement of the parasite clearance phenotype requires frequent timed blood sampling [41]. This is often impractical and means that many surveys only collect information on the $p f k 13$ genotypes in a study area. It is therefore critical to utilize optimally those studies that do include both genotype and in vivo phenotype. The $\mathrm{WHO}$ has provided guidelines for associating $P$. falciparum parasite mutations with slow parasite clearance in vivo [42]. Currently, 6 pfk 13 propeller region mutant alleles have been validated in this way, 8 additional alleles have been described as "associated" with the phenotype, and 18 other alleles have been isolated in such low numbers that their phenotype could not be evaluated. It is also clear that some non-synonymous mutations in the pfk13 propeller region (notably A578S) are not associated with artemisinin resistance. The low prevalence of $p f k 13$ propeller alleles outside the Greater Mekong Subregion has limited our ability to confirm the roles of additional genotypes in conferring the delayed clearance phenotype.

We have used meta-analysis of individual patient data from published and unpublished studies to compare standardized parasite clearance half-life estimates and pfk 13 propeller region genotypes. This analysis capitalized on the power of the large data set to allow assessment of the importance of a broader range of propeller region alleles in mediating slow parasite clearance in vivo.

\section{Methods}

\section{Data acquisition}

A systematic literature review following the PRISMA protocol [43] was conducted to identify studies published between 2000 and 2017 which included frequent parasite measurements and pfk 13 genotyping (last run on 31 January 2018). Four databases (Ovid Medline, PubMed, Ovid Embase, and Web of Science Core Collection) were searched. The search terms and conditions are available in Additional file 1.

At the abstract screening stage, we excluded studies that did not include treatment with artemisinin derivatives, 
pfk13 genotyping or parasite measurements as well as review and correspondence articles. At full-text screening, we excluded additional studies that measured parasites less frequently than twice a day. Data were actively requested only from studies that reported parasites that carried pfk 13 non-synonymous mutations. However, we received two studies that found no parasites that carried these $p f k 13$ mutations and these were analyzed as part of the wild type data set.

Studies that identified non-synonymous mutations in pfk13 were eligible for inclusion in this analysis if individual patient files also met the following criteria: (a) patients were treated with either an $\mathrm{ACT}$ or an artemisinin monotherapy; (b) parasitemia was measured in the first days of treatment at least every $12 \mathrm{~h}$, until a negative count or at least until day 3, allowing the standardized calculation of the $\mathrm{PC}_{1 / 2}[29,30]$; (c) the dosing protocol was available; and (d) the weight of each individual patient was recorded. The published papers and data sources are listed in detail in Additional file 2: Table S1 [2, 11, 15, 16, 19, 44-51].

Individual study protocols were available for all trials included, either from the publication or as a metafile submitted with the primary data. Individual patient data from eligible studies were shared, collated, and standardized under the protocols of the WWARN data platform using previously described methodology [52]. Study reports generated from the formatted datasets were sent back to investigators for validation or clarification. Methodologies used in studies regarding parasitemia sampling and molecular analyses are presented in Additional file 2: Table S1.

\section{Statistical analysis}

The statistical analysis plan [53] was developed before analysis. All non-synonymous mutations in the pfk 13 gene identified in the studies were included in the analysis. Isolates without reported mutations were assumed to be wild type in assessing relationships between parasite genotype and $\mathrm{PC}_{1 / 2}$. Isolates with a mixed genotype at any nucleotide within the $p f k 13$ coding region (wild type/mutation or two non-synonymous mutations) were excluded from the analysis.

The $\mathrm{PC}_{1 / 2}$ is defined as the time in hours needed for the parasite density to decline by $50 \%$ during the log-linear phase of parasite clearance. $\mathrm{PC}_{1 / 2}$ was calculated using the WWARN parasite clearance estimator tool [41]. The goodness of fit of parasite clearance models was evaluated for each individual patient parasitemia-time profile used to estimate the $\mathrm{PC}_{1 / 2}$.

Profiles that satisfied the following criteria (i.e., provided biologically or statistically plausible results) were included in the analysis: (a) standard deviations of residuals $<2$, (b) number of data points used to fit the linear part of the curve $>2$, (c) duration of lag phase $<12 \mathrm{~h}$, (d) pseudo $R^{2}$ statistics $\geq 0.8$. Additionally, patients who withdrew or had a record of inadequate dosing were excluded. The log transformed half-life metric was modeled for all pfk13 mutant alleles in all studies with information from individual patients on age, initial parasitemia, ACT treatment, and artesunate dose as covariates. The method by which the dose was calculated is documented in the statistical analysis plan. Random effects for study site were used to account for heterogeneity between studies. Residuals were examined for normality and for systematic deviations from the model.

The differences in $\mathrm{PC}_{1 / 2}$ between infections with $P$. falciparum parasites bearing a specific pfk13 propeller mutant allele and those with wild type parasites were assessed by the Wald test. The fold change in geometric mean of $\mathrm{PC}_{1 / 2}$ of infections with pfk 13 mutant parasites compared to wild type isolates from the same sites; $x \mathrm{PC}_{1 / 2}$ was calculated as an exponent of the difference of the corresponding regression coefficients.

In order to determine a $\mathrm{PC}_{1 / 2}$ threshold value that defined slow parasite clearance, we divided Asian data into two populations: rapid clearing and slow clearing. The slow-clearing population was defined as all isolates with mutations associated with a significant increase in $\mathrm{PC}_{1 / 2}$ values in this analysis, while the fast-clearing population included all other isolates. The $\mathrm{PC}_{1 / 2}$ value that corresponds to the 95th percentile of the fast-clearing population (i.e., a value $x$ such that the probability that $\mathrm{PC}_{1 / 2}>$ $x$ is less than 0.05) was selected as the cutoff for infections with "slow clearing" parasites. Risk of bias in individual studies was assessed based on frequency of parasite counting, molecular methodology, and number of patients excluded because of missing data or unsatisfactory fit of the model for $\mathrm{PC}_{1 / 2}$ estimation (for details, see Additional file 1). Data from studies/sites that reported results very different from all of the others in the same region were included in the analysis, and a sensitivity analysis was conducted after excluding Tra Lang, Vietnam (study site ID 23; study ID 8), and Pyin Oo Lwin, Myanmar (study site ID 15; study ID 13).

\section{Results}

\section{Literature search}

The literature search identified 146 articles, with 9 satisfying our inclusion criteria and describing data from 14 studies (Additional file 1). Seven additional studies were contributed in response to the proposal for this study group on the WWARN website. Consequently, we requested individual patient data from 21 studies and received data from 18 studies.

\section{Description of the study sites}

There were 16 studies from Asian sites that reported both $\mathrm{PC}_{1 / 2}$ estimates and $p f k 13$ propeller region genotypes from 
Myanmar, Thailand, Cambodia, Lao Peoples Democratic Republic (PDR), Vietnam, Bangladesh, and Yunnan province of China bordering Myanmar. Among these 3179 patients, 3012 had sufficient data for $\mathrm{PC}_{1 / 2}$ estimation and 2631 met the inclusion criteria for evaluation of the association of the $p f k 13$ genotype and the parasite clearance phenotype. Of the Asian isolates, nearly half (43\%; 1142/ 2631) were from four study sites of the Shoklo Malaria Research Unit (SMRU) along the Western Thailand/Eastern Myanmar Border; these isolates are identified as a group called Thai Western Border.

There were 238 isolates with genotype and phenotype information contributed from five sites in Africa; one site in Nigeria $(n=31)$, the Democratic Republic of Congo-DRC $(n=119)$, and Tanzania $(n=39)$; and two sites in Madagascar $(n=49)$. A total of 204 patients' data met the inclusion criteria for evaluation of the association of the $p f k 13$ genotype and the parasite clearance phenotype (Table 1, Figs. 1 and 2).

Figure 1 depicts the locations of the study sites. Additional file 3: Figure S2 summarizes the numbers of individual data sets that met all criteria for inclusion.

Patient characteristics and the numbers of patients treated with artesunate or artemisinin combination therapies are summarized in Table 2. The median age of patients in Asia was 21 years, and 77\% were 12 years of age or older; African patients had a median age of 4.7 years, and only $6 \%$ were older than 11 years.

\section{Molecular analyses of the pfk13 alleles}

Samples were collected between 2001 and 2014. Among the 45 individual study sites, 33 included data from the entire pfk13 gene (codons 1-726); 12 studies reported sequence of only the propeller region codons (441-726). A total of 202 and 1254 isolates with molecular information on mutants in codons 1-440 (P. falciparum-specific region) and codons 441-726 (the propeller region) were recorded respectively. The $p f k 13$ genotype of parasites from 3424 patients was determined; mutant alleles were identified in 1455 samples. The prevalence of mutant codons observed in each study is summarized in Table 1.

\section{Plasmodium-specific region (codons 1-440)}

Data were available for the whole $p f k 13$ molecule in two African study sites: Kinshasa, DRC (study ID 13; site ID 24), and Ilorin, Nigeria (study ID 13; site ID 36). Ilorin had the higher prevalence of isolates with mutant codons in the $P$. falciparum domain $(14 / 36,39 \%)$, compared with Kinshasa (33/117, 28\%). In 76\% (37/49) of these isolates, the mutations were at codon 189; 35 carried the K189T mutation, 12 carried a synonymous $\mathrm{K} 189 \mathrm{~K}$, and 2 carried a K189N codon (Additional file 2: Table S2A).
Complete pfk13 DNA sequence was determined in 18 Asian study sites, including all of the studies from the Thai Western Border. Mutant codons in the $5^{\prime}$ region of the gene were rare in most Asian-derived samples. The K189T mutant codon was observed in samples from Bangladesh (study 7; site 1: $n=1 / 21,5 \%$ ), (study 16; site 2: $n=4 / 55,7 \%)$ and two sites in Myanmar ((study 16; site 16: $n=3 / 74,4 \%)$, study 12 ; site $17: n=1 / 71,(1.4 \%))$ (Additional file 2: Table S2A).

Many of the parasites from the Thai Western Border (site 20) shared an allele with a codon change at position 252 from glutamic acid to glutamine (E252Q). Parasites with this allele were observed in study $1(n=1 / 7,14 \%)$, study 4 ( $n=68 / 950,7 \%)$, and study $16(n=14 / 116,12 \%)$. Parasites with this genotype were also observed in Shwe Kyin in 2011-2013 (study 16, site 16), where they comprised 10/74 (14\%) of the isolates tested (Additional file 2: Table S2A), and this allele has been observed near the Myanmar-China border, as well [14]. In the relatively conserved stem domain (350-440), mutants were observed only transiently in parasites from Shwe Kyin and the Thai Western Border.

\section{pfk13 propeller region (codons 441-726)}

The sequence of the $p f k 13$ propeller region was determined in all 45 data sets (Table 1, Additional file 2: Table S2B). In the African isolates, the only mutant codons identified in the propeller region were in $3 / 117$ isolates from Kinshasa, each with a single mutation (codons S522C, A578S, or Q613L) and in 4/44 isolates from Brickaville, Madagascar, all with mutant codon A578S which is relatively common in Africa and has been reported in Thailand and Bangladesh [27]. The Asian data set was dominated by large numbers of patients from two regions, the Thai Western Border $(n=$ $1291 / 3087(42 \%))$ and northwestern Cambodia $(n=847 /$ 3087 (27\%)), with smaller numbers from Vietnam, Myanmar, the Myanmar-China Border, Bangladesh, and Lao PDR. The detailed data are summarized in Additional file 2: Table S2B. As has been published, the Thai Western Border, Thai, Cambodian, Laotian, and Vietnamese data sets contained numerous isolates with the pfk 13 C580Y allele $[11-14,18,19,21,22,28,32,34$, $50,54,55]$. In contrast, isolates with the $\mathrm{Y} 493 \mathrm{H}$ and R539T mutant codons were common among Cambodian isolates, but uncommon in samples from Thailand with the exception of those from Srisaket, a province that borders Cambodia.

The F446I mutant predominated in data sets from Myanmar and the China/Myanmar border $(n=83 / 141$, (59\%) $[14,16,27,51]$. The mutant codons in the propeller region identified among the African isolates, S522C, S613E, and the very common A578S "African" allele, were absent from the Asian data set. 
Table 1 Summary of genotyping results by study site. Samples with mixed genotyping are excluded. Details of mutations are listed in Additional file 2: Table S2A (codons 1-440) and S2B (codons 441-726), and mixed genotypes are listed in Additional file 2: Table S3. Results are sorted by continent, country, site, and year of study

\begin{tabular}{|c|c|c|c|c|c|c|c|c|}
\hline \multirow[t]{3}{*}{ Study ID } & \multirow[t]{3}{*}{ Country } & \multirow[t]{3}{*}{ Site ID } & \multirow[t]{3}{*}{ Site } & \multirow[t]{3}{*}{ Year } & \multirow{3}{*}{$\begin{array}{l}\text { Total } N \\
\text { isolates }\end{array}$} & \multicolumn{3}{|c|}{ Non-synonymous changes between } \\
\hline & & & & & & \multirow{2}{*}{$\begin{array}{l}\text { Codon 1-440 } \\
N\end{array}$} & \multicolumn{2}{|c|}{ Codon 441-726 } \\
\hline & & & & & & & $N$ & $\%[95 \% \mathrm{Cl}]$ \\
\hline \multicolumn{9}{|l|}{ Asia } \\
\hline 7 & Bangladesh & 1 & Bandarban & 2004-2005 & 21 & 2 & 0 & $0[0-15]$ \\
\hline 16 & Bangladesh & 2 & Ramu & 2012 & 55 & 4 & 0 & $0[0-7]$ \\
\hline 9 & Cambodia & 3 & Anlong Veng & $2012-2014$ & 107 & ND & 103 & 96 [91-99] \\
\hline 2 & Cambodia & 4 & Tasanh & 2008-2009 & 46 & ND & 38 & 83 [69-91] \\
\hline 6 & Cambodia & 5 & Pailin & 2008-2009 & 36 & ND & 34 & 94 [82-98] \\
\hline 16 & Cambodia & 5 & Pailin & $2011-2012$ & 87 & 0 & 80 & 92 [84-96] \\
\hline 10 & Cambodia & 6 & Preah Vihear & 2012-2013 & 65 & ND & 22 & 34 [24-46] \\
\hline 11 & Cambodia & 6 & Preah Vihear & 2011-2012 & 110 & 0 & 22 & 20 [14-28] \\
\hline 10 & Cambodia & 7 & Pursat & 2012-2013 & 107 & ND & 82 & 77 [68-84] \\
\hline 16 & Cambodia & 7 & Pursat & 2011-2012 & 104 & 0 & 77 & 74 [65-82] \\
\hline 10 & Cambodia & 8 & Ratanakiri & 2012-2013 & 66 & ND & 7 & 11 [5-20] \\
\hline 16 & Cambodia & 8 & Ratanakiri & 2011-2012 & 119 & 0 & 4 & $3[1-8]$ \\
\hline 11 & China & 9 & Tengchong & 2012 & 12 & ND & 10 & 83 [55-95] \\
\hline 11 & China & 10 & Yingjiang & 2009-2012 & 110 & ND & 61 & 55 [46-64] \\
\hline 12 & LPDR & 11 & Attapeu & 2013-2014 & 18 & 0 & 4 & 22 [9-45] \\
\hline 14 & LPDR & 11 & Attapeu & 2011-2012 & 118 & 0 & 2 & $2[0-6]$ \\
\hline 3 & LPDR & 12 & Savannakhet & 2010 & 33 & 0 & 0 & $0[0-10]$ \\
\hline 15 & Myanmar & 13 & Hpa Pun & 2013 & 32 & 1 & 14 & 44 [28-61] \\
\hline 12 & Myanmar & 14 & Myitkyina & 2013-2014 & 43 & 0 & 21 & 49 [35-63] \\
\hline 13 & Myanmar & 15 & Pyin Oo Lwin & 2012-2014 & 31 & 0 & 15 & 48 [32-65] \\
\hline 16 & Myanmar & 16 & Shwe Kyin & $2011-2013$ & 74 & 17 & 20 & 27 [18-38] \\
\hline 12 & Myanmar & 17 & Thabeikkyin & 2013-2014 & 71 & 1 & 12 & 17 [10-27] \\
\hline 16 & Thailand & 18 & Ranong & 2011-2012 & 19 & 0 & 13 & 68 [46-85] \\
\hline 16 & Thailand & 19 & Srisaket & 2011-2013 & 34 & 0 & 30 & 88 [73-95] \\
\hline 4 & Thailand & 20 & TW border & 2001 & 9 & 0 & 0 & 0 [0-30] \\
\hline 4 & Thailand & 20 & TW border & 2002 & 58 & 0 & 0 & $0[0-6]$ \\
\hline 4 & Thailand & 20 & TW border & 2003 & 33 & 3 & 0 & $0[0-10]$ \\
\hline 4 & Thailand & 20 & TW border & 2004-2006 & 28 & 0 & 0 & 0 [0-12] \\
\hline 4 & Thailand & 20 & TW border & 2007 & 26 & 2 & 1 & 4 [1-19] \\
\hline 4 & Thailand & 20 & TW border & 2008 & 341 & 30 & 57 & 17 [13-21] \\
\hline 1 & Thailand & 20 & TW border & 2008 & 5 & 1 & 1 & 20 [4-62] \\
\hline 4 & Thailand & 20 & TW border & 2009 & 227 & 38 & 47 & 21 [16-26] \\
\hline 4 & Thailand & 20 & TW border & 2010 & 138 & 20 & 46 & $33[26-42]$ \\
\hline 4 & Thailand & 20 & TW border & 2011 & 113 & 17 & 66 & 58 [49-67] \\
\hline 16 & Thailand & 20 & TW border & $2011-2012$ & 94 & 5 & 61 & 65 [55-74] \\
\hline 4 & Thailand & 20 & TW border & 2012 & 116 & 14 & 80 & 69 [60-77] \\
\hline 4 & Thailand & 20 & TW border & 2013 & 80 & 1 & 67 & 84 [74-90] \\
\hline 4 & Thailand & 20 & TW border & 2014 & 23 & 0 & 21 & 91 [73-98] \\
\hline 16 & Viet Nam & 21 & Binh Phuoc & $2011-2012$ & 103 & 0 & 28 & $27[20-36]$ \\
\hline
\end{tabular}


Table 1 Summary of genotyping results by study site. Samples with mixed genotyping are excluded. Details of mutations are listed in Additional file 2: Table S2A (codons 1-440) and S2B (codons 441-726), and mixed genotypes are listed in Additional file 2: Table S3. Results are sorted by continent, country, site, and year of study (Continued)

\begin{tabular}{|c|c|c|c|c|c|c|c|c|}
\hline \multirow[t]{3}{*}{ Study ID } & \multirow[t]{3}{*}{ Country } & \multirow[t]{3}{*}{ Site ID } & \multirow[t]{3}{*}{ Site } & \multirow[t]{3}{*}{ Year } & \multirow{3}{*}{$\begin{array}{l}\text { Total } N \\
\text { isolates }\end{array}$} & \multicolumn{3}{|c|}{ Non-synonymous changes between } \\
\hline & & & & & & \multirow{2}{*}{$\begin{array}{l}\text { Codon 1-440 } \\
N\end{array}$} & \multicolumn{2}{|c|}{ Codon $441-726$} \\
\hline & & & & & & & $N$ & $\%[95 \% \mathrm{Cl}]$ \\
\hline 5 & Viet Nam & 22 & Phuoc Long & $2010-2011$ & 92 & 0 & 34 & $37[28-47]$ \\
\hline 8 & Viet Nam & 23 & Tra Lang & 2012 & 83 & ND & 67 & $81[71-88]$ \\
\hline \multicolumn{9}{|l|}{ Africa } \\
\hline 16 & DRC & 24 & Kinshasa & 2013 & 117 & 32 & 3 & $3[1-7]$ \\
\hline 18 & Madagascar & 25 & Ankazobe & 2014 & 5 & ND & 0 & $0[0-43]$ \\
\hline 18 & Madagascar & 26 & Brickaville & 2014 & 44 & ND & 4 & $9[4-21]$ \\
\hline 16 & Nigeria & 27 & Ilorin & $2011-2012$ & 36 & 14 & 0 & 0 [0-10] \\
\hline 17 & Tanzania & 28 & Fukayosi & 2012 & 41 & ND & 0 & 0 [0-10] \\
\hline
\end{tabular}

DRC Democratic Republic of Congo, LPDR Lao People's Democratic Republic, TW border Thai Western border, ND not done

\section{Association of pfk13 mutations and parasite clearance half-life}

Among 3329 patients with pfk13 genotyping results that reported only a single mutation in the propeller region, $\mathrm{PC}_{1 / 2}$ values were estimated in 3156 (95\%) patients. In 165 patients, $\mathrm{PC}_{1 / 2}$ could not be estimated because the data were too sparse, the initial parasitemia was too low $(<100$ parasites per microliter) $(n=3)$ or the last recorded parasitemia was too high ( $>10,000$ parasites per microliter) $(n$ =6). Overall, $90 \%$ (2834 of 3156 ) of $\mathrm{PC}_{1 / 2}$ estimates were classified as suitable for analysis (using criteria specified prospectively in the methods, and Fig. 2).

\section{Defining the groups of slow- and fast-clearing parasites} Two populations of parasites were identified among the Asian parasites: fast-clearing $\left(\log _{\mathrm{e}} \mathrm{PC}_{1 / 2}\right.$ mean, $1.0 \mathrm{SD}$,
0.41) and slow-clearing including all isolates with mutations listed in Tables 3 and $7\left(\log _{\mathrm{e}} \mathrm{PC}_{1 / 2}\right.$ mean 1.9; SD $0.19)$. These groups had corresponding half-life geometric means of $2.7 \mathrm{~h}$ and $6.7 \mathrm{~h}$, respectively. $\mathrm{A} \mathrm{PC}_{1 / 2}$ equal to $5.5 \mathrm{~h}$ corresponds to the 95th percentile of the fast-clearing parasite population, and the probability of observing $\mathrm{PC}_{1 / 2}>5.5 \mathrm{~h}$ in a single isolate coming from a sensitive population is equal to 0.043 . On this basis, a median value of $\mathrm{PC}_{1 / 2}>5.5 \mathrm{~h}$ was used to define parasites associated with slow clearance.

\section{African isolates}

Summary statistics of $\mathrm{PC}_{1 / 2}$ estimates and their association with $p f k 13$ mutations are presented in Table 5 and Additional file 3: Figure S3A for wild type (median $\mathrm{PC}_{1 / 2}$

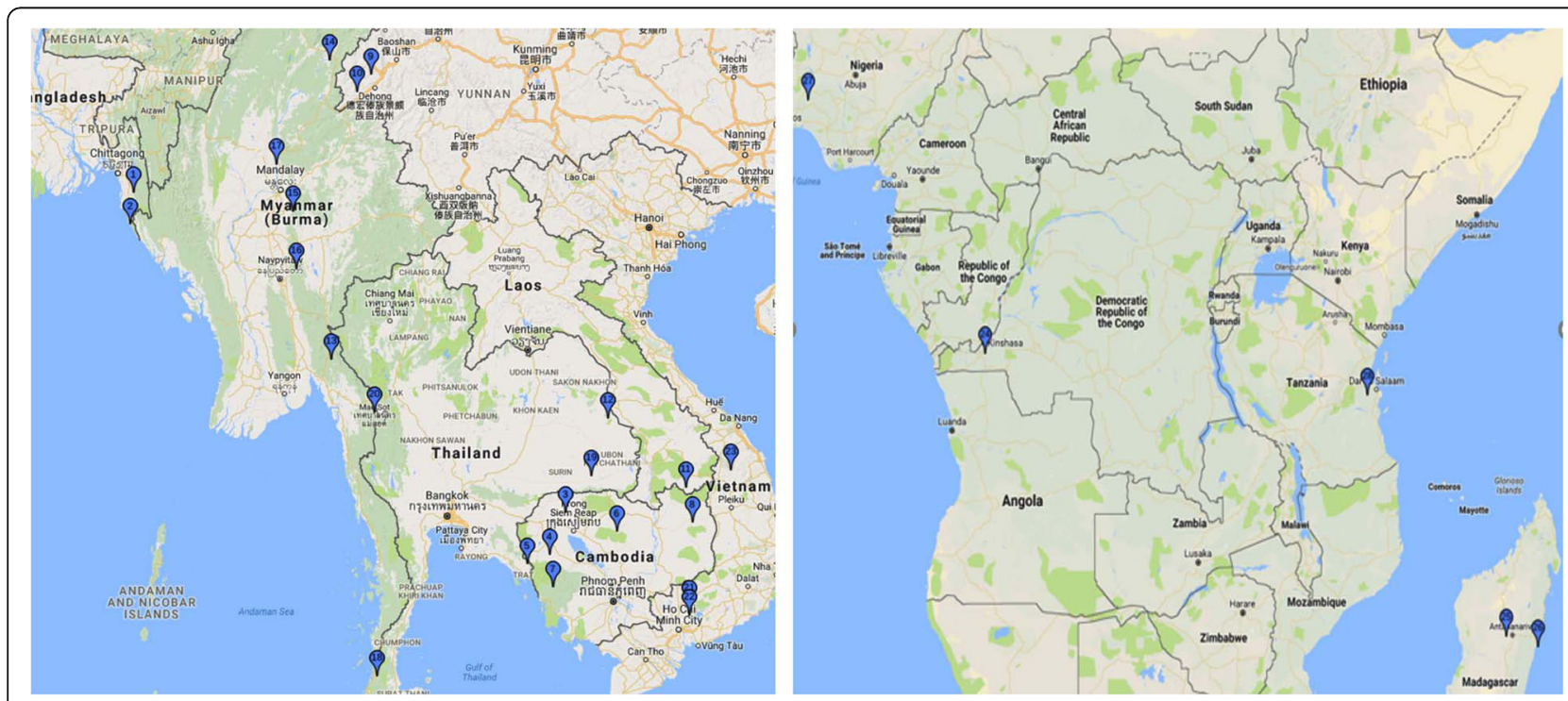

Fig. 1 Study site locations. The numbers in the pins correspond to the study sites listed in Table 1 


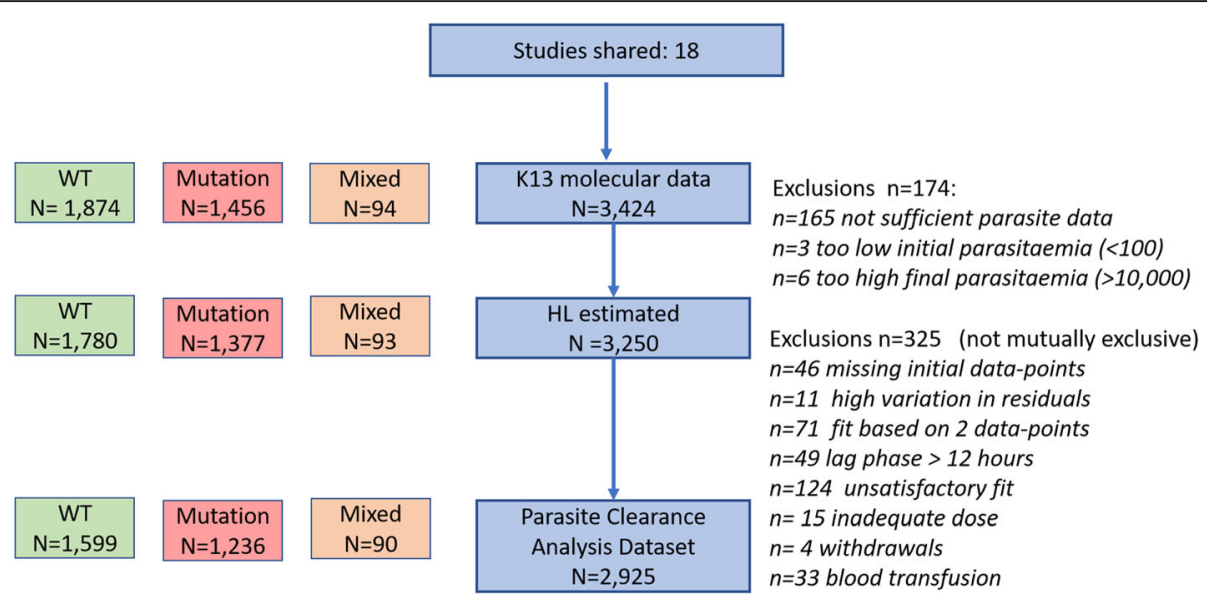

Fig. 2 Study profile. Definitions for specific exclusions are listed at the right of the figure detailing the number of isolates included in each analysis. Unsatisfactory fit was defined as pseudo- $R^{2}$ statistics $<0.8$. Insufficient parasite data includes patients with too few observations to fit the model and patients with only daily counts

$2.2 \mathrm{~h}$, range $0.7-6.3$ ) and mutant $\mathrm{K} 189 \mathrm{~T}$ (median $\mathrm{PC}_{1 / 2}$ $2.1 \mathrm{~h}$, range 0.8-7.1). Additional file 3: Figure S3B shows individual $\mathrm{PC}_{1 / 2}$ values for all other mutations observed in African isolates.

The $\mathrm{PC}_{1 / 2}$ values in wild type isolates from the five African sites were all well below the cutoff of $5.5 \mathrm{~h}$, but varied significantly from one another $(p=0.004$, Additional file 3 : Figure S1). Compared to wild type isolates in Kinshasa, DRC, an area of high perennial transmission, the $\mathrm{PC}_{1 / 2}$ in wild type isolates was 1.36 times longer $(95 \% \mathrm{CI} 1.08-1.70 ; p=$
0.008) in Brickaville, Madagascar, 1.46 times longer (95\%CI $1.18-1.8 ; p=0.001)$ in Ilorin, Nigeria; and not significantly different in Fukayosi, Tanzania $(p=0.117)$, or Ankazobe, Madagascar $(p=0.199)$ (Additional file 3: Figure S1).

Most $p f k 13$ mutations were rare in the African data sets, being observed in fewer than four isolates (Figure 3). Among a total of seven isolates with a propeller mutation (S522C, A578S, or Q613L), four met the inclusion criteria for evaluation of the association of the pfk 13 genotype and the parasite clearance phenotype. All of

Table 2 Baseline characteristics and treatment administered. Only patients with genotyping and $\mathrm{PC}_{1 / 2}$ results are presented

\begin{tabular}{|c|c|c|c|c|}
\hline & \multicolumn{2}{|l|}{ Asia } & \multicolumn{2}{|c|}{ Africa } \\
\hline & N & Median (range) or N (\%) & $N$ & $N(\%)$ or median (range) \\
\hline Age (years) & 2630 & $21[0.1-70]$ & 204 & $4.7[0.7-29]$ \\
\hline$<1$ year & & $8[0]$ & & $11[5]$ \\
\hline $1-4$ years & & $185[7]$ & & $98[48]$ \\
\hline $5-11$ years & & $407[15]$ & & $82[40]$ \\
\hline $12+$ years & & $2030[77]$ & & $13[6]$ \\
\hline Parasitemia (microliter) & 2631 & $97,214[455-2,409,008]$ & 204 & $53,507[2240-605,329]$ \\
\hline Temperature (C) & 1658 & $38.2[34.1-41.5]$ & 204 & $37.6[34.7-40.8]$ \\
\hline Hemoglobin (g/dL) & 770 & $13.1[2.1-19.3]$ & 26 & $10.8[6.3-14.2]$ \\
\hline Hematocrit (\%) & 1542 & $40[12-55]$ & 140 & $31[21-44]$ \\
\hline \multicolumn{5}{|c|}{ Artemisinin derivative: total 3 days dose (mg/kg) } \\
\hline$A L$ & 0 & & 80 & $9.3[5.2-16.0]$ \\
\hline AS & 433 & 8.3 [1.0-49.7] & 0 & \\
\hline $\mathrm{AS}+\mathrm{ACT}^{1}$ & 1638 & 8.3 [0.5-28.9] & 83 & $11.8[4.7-15]$ \\
\hline ASAQ & 0 & & 41 & 13.0 [8.6-16.7] \\
\hline ASMQ & 81 & 8.0 [3.8-16.1] & 0 & \\
\hline DHAPIP & 430 & 6.7 [3.0-17.8] & 0 & \\
\hline
\end{tabular}


Table 3 Comparison of $\mathrm{PC}_{1 / 2}$ between patients with WT and a pfk 13 NS-mutation in Asia. Metric is the fold increase of $P C_{1 / 2}$ in mutants vs. wild type. Only mutations with $n \geq 5$ are shown. With only two exceptions (K189T and K438N), all patients that carried parasites with the indicated pfk13 mutant codon showed a $\mathrm{PC}_{1 / 2}$ significantly different from those that carried WT parasites

\begin{tabular}{|c|c|c|c|c|c|c|c|c|}
\hline \multirow[b]{3}{*}{ Codon } & \multirow{3}{*}{$\begin{array}{l}N \text { with } \\
\text { mutation }\end{array}$} & \multirow{3}{*}{$\begin{array}{l}N \text { with } \\
\text { WT }\end{array}$} & \multicolumn{6}{|c|}{ Comparison of $\mathrm{PC}_{1 / 2}$} \\
\hline & & & \multicolumn{3}{|c|}{ Univariable } & \multicolumn{3}{|c|}{ Multivariable $^{1}$} \\
\hline & & & $x \mathrm{PC}_{1 / 2}$ & $95 \% \mathrm{Cl}$ & $p$ value & $x \mathrm{PC}_{1 / 2}$ & $95 \% \mathrm{Cl}$ & $p$ value \\
\hline K189T & 8 & 148 & 1.1 & $0.8-1.4$ & 0.729 & 1.1 & $0.8-1.4$ & 0.644 \\
\hline E252Q & 114 & 589 & 1.5 & $1.4-1.6$ & $<0.001$ & 1.5 & $1.4-1.6$ & $<0.001$ \\
\hline K438N & 10 & 386 & 0.9 & $0.7-1.1$ & 0.251 & 0.9 & $0.7-1.1$ & 0.237 \\
\hline P441L & 53 & 565 & 2.1 & $1.9-2.3$ & $<0.001$ & 2.2 & $2.0-2.4$ & $<0.001$ \\
\hline F446l & 79 & 303 & 1.6 & $1.4-1.7$ & $<0.001$ & 1.5 & $1.4-1.7$ & $<0.001$ \\
\hline G449A & 6 & 41 & 1.9 & $1.4-2.6$ & $<0.001$ & 1.9 & $1.3-2.7$ & $<0.001$ \\
\hline N458Y & 34 & 520 & 2.5 & $2.2-2.8$ & $<0.001$ & 2.5 & $2.2-2.8$ & $<0.001$ \\
\hline M476l & 8 & 481 & 2 & $1.6-2.5$ & $<0.001$ & 2.0 & $1.5-2.5$ & $<0.001$ \\
\hline A481V & 5 & 410 & 1.8 & $1.3-2.4$ & $<0.001$ & 1.6 & $1.2-2.2$ & 0.002 \\
\hline $\mathrm{Y} 493 \mathrm{H}$ & 33 & 313 & 2.6 & $2.2-3.0$ & $<0.001$ & 2.7 & $2.3-3.1$ & $<0.001$ \\
\hline R515K & 5 & 352 & 1.9 & $1.4-2.6$ & $<0.001$ & 2.0 & $1.5-2.7$ & $<0.001$ \\
\hline $\mathrm{P} 527 \mathrm{H} / \mathrm{L}^{*}$ & 23 & 422 & 1.7 & $1.5-2.0$ & $<0.001$ & 1.7 & $1.5-2.0$ & $<0.001$ \\
\hline N537I & 8 & 231 & 1.7 & $1.3-2.2$ & $<0.001$ & 1.8 & $1.4-2.3$ & $<0.001$ \\
\hline G538V & 24 & 558 & 1.8 & $1.6-2.1$ & $<0.001$ & 1.9 & $1.6-2.2$ & $<0.001$ \\
\hline R539T & 76 & 369 & 2.1 & $1.9-2.4$ & $<0.001$ & 2.1 & $1.9-2.4$ & $<0.001$ \\
\hline I543T & 92 & 156 & 1.9 & $1.7-2.3$ & $<0.001$ & 2.1 & $1.8-2.4$ & $<0.001$ \\
\hline $1543 T^{* *}$ & 27 & 140 & 2.8 & $2.3-3.4$ & $<0.001$ & 2.8 & $2.3-3.5$ & $<0.001$ \\
\hline P553L & 16 & 529 & 2.2 & $1.8-2.6$ & $<0.001$ & 2.2 & $1.8-2.8$ & $<0.001$ \\
\hline $\mathrm{R} 561 \mathrm{H}$ & 36 & 310 & 2.2 & $1.9-2.5$ & $<0.001$ & 2.2 & $1.9-2.6$ & $<0.001$ \\
\hline V568G & 5 & 127 & 2.7 & $1.8-4.1$ & $<0.001$ & 2.7 & $1.8-4.1$ & $<0.001$ \\
\hline P574L & 48 & 739 & 1.8 & $1.6-2.0$ & $<0.001$ & 2.0 & $1.7-2.2$ & $<0.001$ \\
\hline P574L*** & 35 & 723 & 1.8 & $1.6-2.1$ & $<0.001$ & 1.8 & $1.6-2.1$ & $<0.001$ \\
\hline C580Y & 450 & 997 & 2.2 & $2.1-2.4$ & $<0.001$ & 2.3 & $2.1-2.4$ & $<0.001$ \\
\hline P667T**** & 5 & 50 & 2.2 & $1.6-2.9$ & $<0.001$ & 2.1 & $1.6-2.9$ & $<0.001$ \\
\hline A675V & 49 & 501 & 2.2 & $1.9-2.4$ & $<0.001$ & 2.2 & $2.0-2.4$ & $<0.001$ \\
\hline
\end{tabular}

${ }^{1}$ Adjusted for total artemisinin derivative dose in the first 3 days, partner drug, initial parasitemia and patient age

*20 P527H, one P527L, analyzed together, two P527H not analyzed since clearance data did not meet criteria

**With study ID 8, study site ID 23 (Tra Lang) removed

***With study ID 13, study site ID 15 (Pyin Oo Lwin) removed

****5 P667T, one P667T not analyzed since clearance data did not meet criteria

the seven isolates had $\mathrm{PC}_{1 / 2}<2.8 \mathrm{~h}$ and exhibited no increase in $\mathrm{PC}_{1 / 2}$ compared to infections with wild type parasites. In fact, the geometric mean of $\mathrm{PC}_{1 / 2}$ was lower in isolates with propeller mutations compared to wild type isolates at the same study sites $(p=0.491$ and $p=$ 0.096 when seven or four isolates were included). In this dataset, only the A578S allele of the propeller mutations observed in Africa was also observed in Asia, but in only three isolates. The median half-life for mutations anywhere in the $p f k 13$ gene ranged from 1.7 to $2.7 \mathrm{~h}$ (Additional file 3: Figure S3A and S3B).

Codon $\mathrm{K} 189 \mathrm{~T} / \mathrm{N}$ was present in 33 isolates (31 were $\mathrm{K} 189 \mathrm{~T}$ and 2 were $\mathrm{K} 189 \mathrm{~N})$, sufficient numbers to assess the overall parasite clearance; these infections had a median
$\mathrm{PC}_{1 / 2}$ of $2.1 \mathrm{~h}$ (range $0.8-7.1$ ) similar to that of infections with wild type parasites; $2.2 \mathrm{~h}$ (range 0.7-6.3) (Fig. 3a).

\section{Asian isolates}

Among Asian isolates, 1440 were wild type and 1190 carried a single $p f k 13$ mutation. The prevalence of isolates with a $\mathrm{PC}_{1 / 2}>5.5 \mathrm{~h}$ and the median $\mathrm{PC}_{1 / 2}$ both varied depending on the pfk13 mutation (Table 5, Fig. 4).

The 32 studies with infections caused by $P$. falciparum isolates that carried a non-synonymous change within codons 1-440 were analyzed, and all 45 studies with sequence information on the propeller regions were analyzed.

Variance in $\mathrm{PC}_{1 / 2}$ between genotypes was significantly larger than within genotypes $\left(F_{40,2554}=48.43, p<0.001\right.$, 

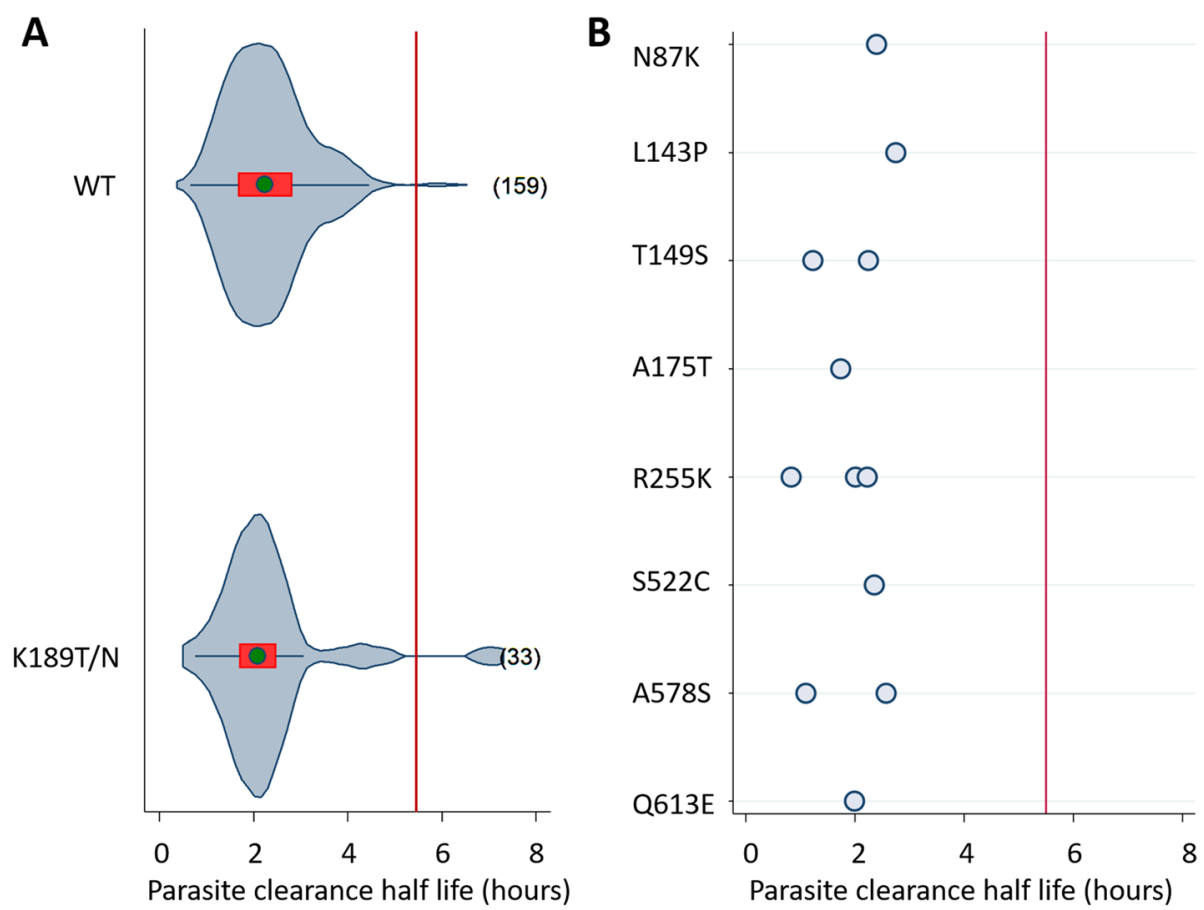

Fig. 3 Distribution of parasite clearance half-life by individual wild type or pfk13 mutant codons in isolates from Africa. Left panel (a) shows violin plots for wild type or mutant codons with five or more isolates. The number of individual isolates tested is at the right of each violin plot. The right panel (b) shows dot plots for mutant codons with $<5$ isolates. The red line shows a half-life of $5.5 \mathrm{~h}$. The median is shown as a green circle, the red bar corresponds to the interquartile range, and the curve represents kernel estimate of the density function

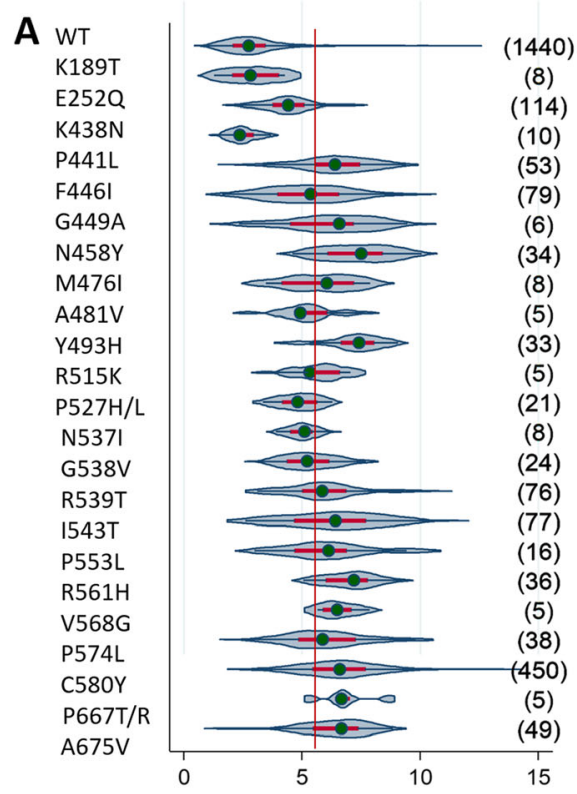

Parasite clearance half life (hours)

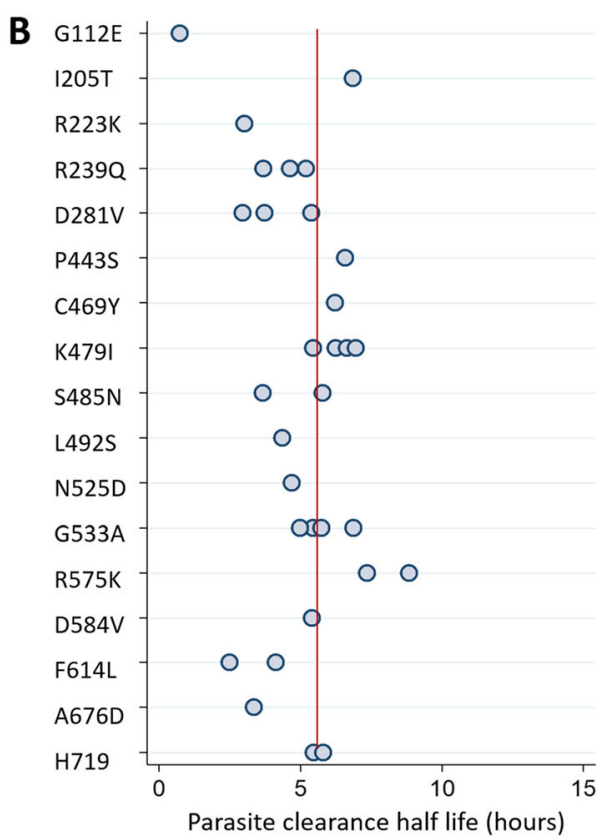

Fig. 4 Distribution of parasite clearance half-life by pfk13 mutant codons in isolates from Asia. Left panel (a) shows violin plots for mutant codons with five or more isolates. The number of individual isolates tested is at the right of each violin plot. The right panel (b) shows dot plots for mutant codons with $<5$ isolates. The red line shows a half-life of $5.5 \mathrm{~h}$. The median is shown as a green circle, the red bar corresponds to the interquartile range, and the curve represents kernel estimate of the density function. * $22 \mathrm{P} 527 \mathrm{H}$ and $1 \mathrm{P} 527 \mathrm{~L}$ with PC1/2 = 5.8h; ** 6 P667T and 1 P667R without valid PC1/2 measurement, so not considered 
after adjusting for study site). All infections with $p f k 13$ mutants in the propeller region that were reported in five or more isolates were associated significantly with a geometric mean $\mathrm{PC}_{1 / 2}$ greater than that in infections with wild type parasites $(p<0.001$ for all but codon $\mathrm{A} 481 \mathrm{~V}$, in which $p=0.002$ ). The fold increase in geometric mean of $\mathrm{PC}_{1 / 2}\left(x \mathrm{PC}_{1 / 2}\right)$, compared to the $\mathrm{PC}_{1 / 2}$ of wild type parasites at the same sites, ranged from 1.5 to 2.7 (Table 3). Parasites with mutations F446I, G449A, A481V, P527L, N537I, G538V, and P574L had a fold increase between 1.5 and 1.9, and all others were between 2.0 and 2.7. Neither isolates with the K189T mutation nor $\mathrm{K} 438 \mathrm{~N}$ showed any increase in $\mathrm{PC}_{1 / 2}$ compared with wild type parasites $(p=0.644$ and 0.237 , respectively). However, isolates with the E252Q mutation (which is also outside the propeller region) from both the Western Thai Border and Shwe Kyin, Myanmar, had a significant increase in $\mathrm{PC}_{1 / 2}, 1.5$-fold $\left(x \mathrm{PC}_{1 / 2}=1.5\right.$; 95\%CI 1.4-1.6) compared with wild type parasites $(p<0.001)$.

For infections caused by parasites that carried only wild type $p f k 13$, the distribution of $\mathrm{PC}_{1 / 2}$ values varied significantly between locations (Additional file 3: Figure S2, $p<0.001$ ); one site in Myanmar, Pyin Oo Lwin, and one in Vietnam, Tra Lang, had a median $\mathrm{PC}_{1 / 2}$ of wild type isolates that was above the cutoff of $5.5 \mathrm{~h}$ and above the $\mathrm{PC}_{1 / 2}$ observed for wild types in other sites $(p<$ 0.001). At both sites, no significant differences were observed in $\mathrm{PC}_{1 / 2}$ between $\mathrm{K} 13$ wild type and $\mathrm{K} 13$ mutant isolates. The corresponding factor for change in $\mathrm{PC}_{1 / 2}$ in mutant isolates was estimated as $0.91(0.74-1.12) p=$ 0.367 for Tra Lang, Vietnam, and $0.90(0.73-1.10) p=$ 0.274 for Myanmar, Pyin Oo Lwin. Four mutant $p f k 13$ alleles were associated with significant differences in $\mathrm{PC}_{1 / 2}$ between different study sites: E252Q $(p<0.001)$, F446I $(p=0.005)$, M476I $(p=0.014)$, Y493H $(p=$ $0.029)$ and C580Y $(p<0.001)$ (Table 4, Additional file 3: Figures S3-S7).

Between 2009 and 2014, the prevalence of the C580Y allele in parasite populations on the Thailand western border increased [18]. This change was accompanied by a progressive increase in the median $\mathrm{PC}_{1 / 2}$ of infections with $p f k 13$ C580Y mutants, from a median of $5.4 \mathrm{~h}$ in 2009 to $7.2 \mathrm{~h}$ in 2014 (Additional file 3: Figure S8). A linear trend of increase in the geometric mean of $\mathrm{PC}_{1 / 2}$ by $5.0 \%(95 \% \mathrm{CI} 2.3-7.9)$ each year $\left(x \mathrm{PC}_{1 / 2}=1.05 ; 95 \%\right.$ CI $1.02-1.08)$ was observed $(p<0.001)$, and the linear trend was not affected by differences in patient treatment or artemisinin derivative dose.

\section{Influence of patient characteristics and antimalarial} treatment drugs on $\mathrm{PC}_{1 / 2}$ in Asian isolates

Differences between $\mathrm{PC}_{1 / 2}$ values for parasites with the same $p f p k 13$ genotype were not significant when adjusted for patients' initial parasitemia, artesunate dose,
Table 4 Comparison of $\mathrm{PC}_{1 / 2}$ for pfk13 NS mutations between study sites in Asia. Only mutations with isolates available from at least five patients from at least two sites are shown

\begin{tabular}{|c|c|c|c|c|}
\hline \multirow{2}{*}{$\begin{array}{l}\text { Mutant } \\
\text { codon }\end{array}$} & \multirow{2}{*}{$\begin{array}{l}N \\
\text { sites }\end{array}$} & \multirow{2}{*}{$\begin{array}{l}N \\
\text { patients }\end{array}$} & \multicolumn{2}{|c|}{$p$ value for comparison by site } \\
\hline & & & Univariable & Multivariable $^{1}$ \\
\hline$\overline{\mathrm{K} 189 \mathrm{~T}}$ & 3 & 8 & 0.324 & 0.278 \\
\hline E252Q & 2 & 114 & $<0.001$ & $<0.001$ \\
\hline $\mathrm{K} 438 \mathrm{~N}$ & 2 & 10 & 0.007 & 0.322 \\
\hline P441L & 3 & 53 & 0.991 & 0.908 \\
\hline F446l & 7 & 79 & 0.002 & 0.005 \\
\hline G449A & 3 & 6 & 0.013 & No data ${ }^{2}$ \\
\hline N458Y & 2 & 34 & 0.583 & 0.249 \\
\hline M476l & 3 & 8 & $<0.001$ & 0.014 \\
\hline A481V & 2 & 5 & 0.664 & No data ${ }^{2}$ \\
\hline Y493H & 7 & 33 & 0.050 & 0.029 \\
\hline R515K & 2 & 8 & 0.525 & No data ${ }^{2}$ \\
\hline G538V & 2 & 24 & 0.599 & No data ${ }^{2}$ \\
\hline R539T & 9 & 76 & 0.623 & 0.766 \\
\hline I543T & 4 & 77 & 0.084 & 0.821 \\
\hline P553L & 4 & 16 & 0.654 & 0.228 \\
\hline $\mathrm{R} 561 \mathrm{H}$ & 4 & 36 & 0.219 & 0.183 \\
\hline V568G & 2 & 5 & 0.563 & No data ${ }^{2}$ \\
\hline P574L & 7 & 38 & 0.001 & 0.003 \\
\hline C580Y & 13 & 450 & $<0.001$ & $<0.001$ \\
\hline
\end{tabular}

${ }^{1}$ Adjusted for total artemisinin derivative dose in the first 3 days, partner drug, initial parasitemia and patient age

${ }^{2}$ Could not fit multivariable model due to small number of observations, overall or within sites

age, and study site. However, within the data set, patients whose parasite clearance was assessed had been treated with a range of artemisinin derivatives and doses and ACT partner drugs (Table 2). Groups with sufficient numbers of isolates (WT, F446I, Y493H, R539T, I543T, P553L, P574L, C580Y) were compared to assess the effects of the drugs administered on the half-life of parasite clearance. No differences in parasite clearance half-life among these different drug treatments were observed with one exception: the comparison between treatment with artesunate alone and artesunate/mefloquine in isolates with a WT genotype. Infections in patients treated initially with artesunate + mefloquine had a geometric mean $\mathrm{PC}_{1 / 2} 0.8$ times $(95 \% \mathrm{CI} 0.7-0.9, p<$ 0.001 ) shorter than those treated with artesunate alone.

\section{Correspondence of $\mathrm{PC}_{1 / 2}>5.5 \mathrm{~h}$ and day 3 parasitemia}

Collecting frequent parasite counts in patients several times per day is not always feasible, and so recording the proportion of patients that remain parasitemic at day 3 after treatment has been proposed as a simple more practical warning signal for the possible slow clearance phenotype [29, 56]. To assess the correspondence 
Table 5 Summary of $\mathrm{PC}_{1 / 2}$ by mutant codon and region showing proportion of isolates from a study site with $\mathrm{PC}_{1 / 2}>5.5 \mathrm{~h}$ and proportion of Day 3 positive isolates. Mutant codons represented by fewer than 5 isolates are indicated in bold

\begin{tabular}{|c|c|c|c|c|c|c|c|c|c|c|}
\hline & \multirow[t]{2}{*}{$N$} & \multirow{2}{*}{$\begin{array}{l}\text { Patients with } \\
\mathrm{PC}_{1 / 2}>5.5 \mathrm{~h}(\%)\end{array}$} & \multicolumn{7}{|c|}{$\mathrm{PC}_{1 / 2}$ Percentiles (hours) } & \multirow{2}{*}{$\begin{array}{l}\text { Patients positive } \\
\text { on day } 3(\%)\end{array}$} \\
\hline & & & Median & 25 & 75 & 5 & 95 & Min & $\operatorname{Max}$ & \\
\hline \multicolumn{11}{|l|}{ Asia } \\
\hline WT & 1440 & 5 & 2.7 & 2.1 & 3.4 & 1.4 & 5.3 & 0.7 & 12.4 & 9 \\
\hline G112E & 1 & 0 & 0.7 & 0.7 & 0.7 & 0.7 & 0.7 & 0.7 & 0.7 & 0 \\
\hline K189T & 8 & 0 & 2.8 & 2.1 & 4.0 & 1.3 & 4.3 & 1.3 & 4.3 & 0 \\
\hline I205T & 1 & 100 & 6.8 & 6.8 & 6.8 & 6.8 & 6.8 & 6.8 & 6.8 & 100 \\
\hline R223K & 1 & 0 & 3.0 & 3.0 & 3.0 & 3.0 & 3.0 & 3.0 & 3.0 & 0 \\
\hline $\mathrm{R} 239 \mathrm{Q}$ & 3 & 0 & 4.6 & 3.7 & 5.2 & 3.7 & 5.2 & 3.7 & 5.2 & 67 \\
\hline E252Q & 114 & 11 & 4.4 & 3.8 & 5.0 & 2.8 & 6.6 & 2.0 & 7.4 & 46 \\
\hline D281V & 3 & 0 & 3.7 & 2.9 & 5.4 & 2.9 & 5.4 & 2.9 & 5.4 & 33 \\
\hline K438 N & 10 & 0 & 2.4 & 2.2 & 2.9 & 1.4 & 3.7 & 1.4 & 3.7 & 30 \\
\hline P441L & 53 & 75 & 6.4 & 5.6 & 7.4 & 3.5 & 8.9 & 2.0 & 9.4 & 77 \\
\hline P443S & 1 & 100 & 6.6 & 6.6 & 6.6 & 6.6 & 6.6 & 6.6 & 6.6 & 100 \\
\hline F446I & 79 & 47 & 5.4 & 4.0 & 6.5 & 2.3 & 8.6 & 1.6 & 10.0 & 32 \\
\hline G449A & 6 & 67 & 6.6 & 4.5 & 7.1 & 2.3 & 9.5 & 2.3 & 9.5 & 67 \\
\hline N458Y & 34 & 88 & 7.5 & 6.1 & 8.4 & 5.0 & 9.8 & 5.6 & 10.1 & 91 \\
\hline C469Y & 1 & 100 & 6.2 & 6.2 & 6.2 & 6.2 & 6.2 & 6.2 & 6.2 & 100 \\
\hline M476I & 8 & 63 & 6.1 & 4.2 & 7.1 & 3.5 & 7.9 & 3.5 & 7.9 & 71 \\
\hline K479I & 4 & 75 & 6.4 & 5.8 & 6.8 & 5.4 & 7.0 & 5.4 & 7.0 & 100 \\
\hline A481V & 5 & 40 & 4.9 & 4.7 & 6.0 & 2.7 & 7.6 & 2.7 & 7.6 & 40 \\
\hline S485N & 2 & 50 & 4.7 & 3.7 & 5.8 & 3.7 & 5.8 & 3.7 & 5.8 & 50 \\
\hline L492S & 1 & 0 & 4.3 & 4.3 & 4.3 & 4.3 & 4.3 & 4.3 & 4.3 & 0 \\
\hline Y493H & 33 & 82 & 7.4 & 6.7 & 8.0 & 4.3 & 9.0 & 4.3 & 9.1 & 84 \\
\hline R515K & 5 & 40 & 5.3 & 5.3 & 6.6 & 3.5 & 7.1 & 3.5 & 7.1 & 80 \\
\hline N525D & 1 & 0 & 4.7 & 4.7 & 4.7 & 4.7 & 4.7 & 4.7 & 4.7 & 0 \\
\hline $\mathrm{P} 527 \mathrm{H} / \mathrm{L}^{*}$ & 21 & 29 & 4.8 & 4.2 & 5.6 & 3.4 & 6.0 & 3.3 & 6.3 & 67 \\
\hline G533A & 4 & 50 & 5.6 & 5.2 & 6.3 & 5.0 & 6.9 & 5.0 & 6.9 & 100 \\
\hline N537I & 8 & 13 & 5.1 & 4.5 & 5.4 & 3.9 & 6.3 & 3.9 & 6.3 & 63 \\
\hline G538 V & 24 & 46 & 5.2 & 4.4 & 6.1 & 4.2 & 7.2 & 3.1 & 7.7 & 48 \\
\hline R539T & 76 & 61 & 5.8 & 5.0 & 6.8 & 3.3 & 9.3 & 3.1 & 10.9 & 56 \\
\hline I543T & 77 & 70 & 6.4 & 4.7 & 7.7 & 3.0 & 9.2 & 2.6 & 11.3 & 52 \\
\hline P553L & 16 & 69 & 6.1 & 4.7 & 6.8 & 3.0 & 10.1 & 3.0 & 10.1 & 63 \\
\hline $\mathrm{R} 561 \mathrm{H}$ & 36 & 97 & 7.2 & 6.1 & 7.7 & 5.5 & 9.1 & 5.0 & 9.2 & 92 \\
\hline V568G & 5 & 100 & 6.5 & 5.9 & 7.0 & 5.7 & 7.9 & 5.7 & 7.9 & 100 \\
\hline P574L & 38 & 61 & 5.9 & 4.9 & 7.2 & 3.6 & 9.6 & 2.3 & 9.8 & 47 \\
\hline R575K & 2 & 100 & 8.1 & 7.3 & 8.8 & 7.3 & 8.8 & 7.3 & 8.8 & 100 \\
\hline C580Y & 450 & 74 & 6.6 & 5.5 & 7.6 & 4.1 & 9.3 & 2.3 & 13.9 & 75 \\
\hline D584V & 1 & 0 & 5.4 & 5.4 & 5.4 & 5.4 & 5.4 & 5.4 & 5.4 & 100 \\
\hline F614L & 2 & 0 & 3.3 & 2.5 & 4.1 & 2.5 & 4.1 & 2.5 & 4.1 & 50 \\
\hline P667T** & 5 & 80 & 6.7 & 6.5 & 7.0 & 5.3 & 8.7 & 5.3 & 8.7 & 100 \\
\hline
\end{tabular}


Table 5 Summary of $\mathrm{PC}_{1 / 2}$ by mutant codon and region showing proportion of isolates from a study site with $P C_{1 / 2}>5.5 \mathrm{~h}$ and proportion of Day 3 positive isolates. Mutant codons represented by fewer than 5 isolates are indicated in bold (Continued)

\begin{tabular}{|c|c|c|c|c|c|c|c|c|c|c|}
\hline \multirow{3}{*}{ 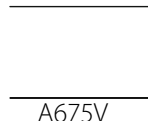 } & \multirow{2}{*}{$N$} & \multirow{2}{*}{$\begin{array}{l}\text { Patients with } \\
\mathrm{PC}_{1 / 2}>5.5 \mathrm{~h}(\%)\end{array}$} & \multicolumn{7}{|c|}{$\mathrm{PC}_{1 / 2}$ Percentiles (hours) } & \multirow{2}{*}{$\begin{array}{l}\text { Patients positive } \\
\text { on day } 3(\%)\end{array}$} \\
\hline & & & $\overline{\text { Median }}$ & 25 & 75 & 5 & 95 & Min & $\overline{\operatorname{Max}}$ & \\
\hline & 49 & 76 & 6.7 & 5.5 & 7.3 & 3.4 & 8.4 & 1.4 & 8.8 & 80 \\
\hline A676D & 1 & 0 & 3.4 & 3.4 & 3.4 & 3.4 & 3.4 & 3.4 & 3.4 & 0 \\
\hline H719N & 2 & 50 & 5.6 & 5.5 & 5.8 & 5.5 & 5.8 & 5.5 & 5.8 & 50 \\
\hline \multicolumn{11}{|l|}{ Africa } \\
\hline WT & 159 & 1 & 2.2 & 1.7 & 2.8 & 1.2 & 4.0 & 0.7 & 6.3 & 1 \\
\hline N87K & 1 & 0 & 2.4 & 2.4 & 2.4 & 2.4 & 2.4 & 2.4 & 2.4 & 0 \\
\hline L143P & 1 & 0 & 2.7 & 2.7 & 2.7 & 2.7 & 2.7 & 2.7 & 2.7 & 0 \\
\hline T149S & 2 & 0 & 1.7 & 1.2 & 2.2 & 1.2 & 2.2 & 1.2 & 2.2 & 0 \\
\hline A175T & 1 & 0 & 1.7 & 1.7 & 1.7 & 1.7 & 1.7 & 1.7 & 1.7 & 0 \\
\hline K189T/N & 33 & 3 & 2.1 & 1.7 & 2.5 & 0.9 & 4.6 & 0.8 & 7.1 & 0 \\
\hline R255K & 3 & 0 & 2.0 & 0.8 & 2.2 & 0.8 & 2.2 & 0.8 & 2.2 & 0 \\
\hline S522C & 1 & 0 & 2.4 & 2.4 & 2.4 & 2.4 & 2.4 & 2.4 & 2.4 & 0 \\
\hline A578S & 2 & 0 & 1.8 & 1.1 & 2.6 & 1.1 & 2.6 & 1.1 & 2.6 & 0 \\
\hline Q613E & 1 & 0 & 2.0 & 2.0 & 2.0 & 2.0 & 2.0 & 2.0 & 2.0 & 0 \\
\hline
\end{tabular}

*20 P527H, one P527L, analyzed together; two P527H not analyzed since clearance data did not meet criteria

**5 P667T; one P667T not analyzed since clearance data did not meet criteria

between these two approaches, the proportion of patients with day 3 parasitemia in these data sets was compared with the proportion of isolates with a $\mathrm{PC}_{1 / 2}>5.5 \mathrm{~h}$ (Table 5, Additional file 3: Figure S9). Use of the day 3 positivity test yielded an overall $11 \%(226 / 1975)$ false positive (FP) rate and 14\% (107/772) false negative (FN) rate when compared to the use of the cutoff of $\mathrm{PC}_{1 / 2}>5.5 \mathrm{~h}$.

However, since the initial parasitemia is a major determinant of time to clear microscopy detectable parasites after treatment, the proportion of FP and FN varies across a range of initial parasitemia values with $51 \% \mathrm{FN}$ for parasite numbers less than $10,000 / \mu \mathrm{L}$ and $29 \% \mathrm{FP}$ for parasite numbers greater than $300,000 / \mu \mathrm{L}$ (Table 6).

Table 6 Utility of day 3 parasite positivity for detection of isolates with long $\mathrm{PC}_{1 / 2}$ (> $5.5 \mathrm{~h}$ ). False positive and false negative outcomes are estimated over a range of initial parasitemia values

\begin{tabular}{llll}
\hline Parasitemia $(/ \mu \mathrm{L})$ & $N$ & $\begin{array}{l}\text { False } \\
\text { positive } \%\end{array}$ & $\begin{array}{l}\text { False } \\
\text { negative } \%\end{array}$ \\
\hline$<10,000$ & 127 & 0 & 51 \\
$10,000-50,000$ & 491 & 3 & 26 \\
$50,000-100,000$ & 804 & 5 & 8 \\
$100,000-300,000$ & 887 & 14 & 3 \\
$\geq 300,000$ & 438 & 29 & 0 \\
All & 2747 & 11 & 14 \\
\hline
\end{tabular}

\section{Association of additional pfk13 mutant alleles with slow parasite clearance}

The current pooled analysis has allowed definition of additional $p f k 13$ genotypes that are associated strongly with slow parasite clearance (Tables 3 and 7). Six pfk13 genotypes have already been associated with slow clearance by WHO, and 11 alleles were listed as candidates [57]. These have all now been demonstrated to be strongly associated with slow clearance $(p<0.001$ except allele A481V, $p=$ 0.002 ). In addition, 6 alleles that previously had been observed infrequently were present in high enough numbers in the analysis data set to allow assessment of the associated $\mathrm{PC}_{1 / 2}$; these alleles also showed a strong association with prolonged parasite clearance. All of the associated mutant alleles had single changes in the $p f k 13$ propeller region, with one exception, allele E252Q, located in the N-terminal Plasmodium-specific region of the protein. Two alleles with a smaller effect on parasite clearance, E252Q and F446I, could now be assessed with confidence since a larger sample size was available $(n=703$ and $n=$ 382 , respectively). Parasites with the $p f k 13$ E252Q mutation had a median $\mathrm{PC}_{1 / 2}$ equal to $4.4 \mathrm{~h}$ and $11 \%$ had a $\mathrm{PC}_{1 / 2}>5.5 \mathrm{~h}$, those that carried a F446I mutation had a median $\mathrm{PC}_{1 / 2}$ of $5.4 \mathrm{~h}$ and $\mathrm{a} \mathrm{PC}_{1 / 2}>5.5 \mathrm{~h}$ was recorded in $47 \%$ of the patients.

\section{Risk of bias}

The risk of bias in individual studies was considered low for majority of studies (Additional file 1). 
Table 7 List of new pfk13 mutant alleles strongly associated with slow parasite clearance

\begin{tabular}{|c|c|c|c|c|c|c|c|}
\hline \multicolumn{2}{|c|}{ WHO designations } & \multicolumn{6}{|l|}{ This paper } \\
\hline Codon & Status & Codon & $N$ total isolates & \# sites & $N$ mutant & \% Prevalence: Median (Range) ${ }^{1}$ & $x \mathrm{PC}_{1 / 2}(95 \% \mathrm{Cl})^{2}$ \\
\hline \multicolumn{8}{|c|}{ pfk13 mutant alleles associated with slow parasite clearance } \\
\hline N458Y & Validated & N458Y & 1118 & 2 & 38 & $3(2-4)$ & $2.5(2.2-2.9)$ \\
\hline Y493H & Validated & Y493H & 638 & 8 & 41 & $4(2-19)$ & $2.7(2.3-3.1)$ \\
\hline R539T & Validated & R539T & 767 & 10 & 80 & $7(2-53)$ & $2.1(1.9-2.4)$ \\
\hline \multirow[t]{2}{*}{ I543T } & Validated & I543T & 323 & 4 & 94 & $13(4-81)$ & $2.1(1.8-2.4)$ \\
\hline & & $1543 T^{*}$ & 240 & 3 & 27 & $10(4-16)$ & $2.8(2.3-3.5)$ \\
\hline $\mathrm{R} 561 \mathrm{H}$ & Validated & $\mathrm{R} 561 \mathrm{H}$ & 1083 & 4 & 42 & $4(3-6)$ & $2.2(1.9-2.6)$ \\
\hline C580Y & Validated & C580Y & 2343 & 14 & 536 & $21(2-75)$ & $2.3(2.1-2.4)$ \\
\hline \multicolumn{8}{|c|}{ pfk13 mutant alleles newly associated with slow clearance phenotype } \\
\hline E252Q & Not assoc & E252Q & 1236 & 2 & 124 & $13(10-16)$ & $1.5(1.4-1.6)$ \\
\hline P441L & Candidate & P441L & 1248 & 3 & 67 & $8(5-10)$ & $2.2(2.0-2.4)$ \\
\hline $\mathrm{F} 446 \mathrm{l}$ & Candidate & F446I & 764 & 7 & 98 & $31(1-67)$ & $1.5(1.4-1.7)$ \\
\hline G449A & Candidate & G449A & 88 & 3 & 7 & $15(3-25)$ & $1.9(1.3-2.7)$ \\
\hline M476l & Low prev & M476l & 886 & 3 & 10 & $3(1-3)$ & $2.0(1.5-2.5)$ \\
\hline A481V & Low prev & A481V & 852 & 3 & 10 & $8(1-9)$ & $1.6(1.2-2.2)$ \\
\hline R515K & Low prev & R515K & 573 & 1 & 6 & $1(1-1)$ & $2.0(1.5-2.7)$ \\
\hline P527H & Low prev & $\mathrm{P} 527 \mathrm{H} / \mathrm{L}^{* *}$ & 711 & 1 & 23 & $3(3-3)$ & $1.7(1.5-2.0)$ \\
\hline N537l/D & Low prev & N537l & 656 & 2 & 10 & $3(1-4)$ & $1.8(1.4-2.4)$ \\
\hline G538V & Candidate & G538V & 1163 & 2 & 27 & $2(2-2)$ & $1.9(1.6-2.2)$ \\
\hline P553L & Candidate & P553L & 1112 & 4 & 18 & $6(1-12)$ & $2.2(1.8-2.8)$ \\
\hline V568G & Candidate & V568G & 195 & 2 & 6 & $3(2-4)$ & $2.7(1.8-4.1)$ \\
\hline \multirow[t]{2}{*}{ P574L } & Candidate & P574L & 1203 & 8 & 48 & $6(2-50)$ & $2.0(1.7-2.2)$ \\
\hline & & P574L*** & 1177 & 7 & 35 & $5(2-17)$ & $1.8(1.6-2.1)$ \\
\hline P667T & Low prev & P667T & 346 & 1 & 7 & $2(2-2)$ & $2.1(1.6-2.9)^{* * * *}$ \\
\hline A675V & Candidate & A675V & 1114 & 1 & 53 & $5(5-5)$ & $2.2(2.0-2.4)$ \\
\hline
\end{tabular}

${ }^{1}$ Prevalence is calculated per study site, combining data from all studies in that location, restricted to range of years when the mutation was observed ${ }^{2}$ Increase in $\mathrm{PC}_{1 / 2}$ compared to wild type; all $p$ values for comparison with $\mathrm{WT}<0.001$. All have a half-life between 1.5 and 2.7 fold greater than the wild type. WHO designations can be found in [57]

*With study ID 8, study site ID 23 (Tra Lang) removed

**20 P527H, one P527L, analyzed together, two P527H not analyzed since clearance data did not meet criteria

***With study ID 13, study site ID 15 (Pyin Oo Lwin) removed

****6 P667T, 1 P667R not analyzed since clearance data did not meet criteria

Sensitivity analysis performed after exclusion of the only study (study ID 8, site ID 23) with moderate risk of bias due to genotyping methods shows the same results as analysis on the full dataset (Table 3). Only the mutant codon I543T was reported at this study/site. Additionally, one study site (study ID 13, site ID 15) presented significantly different $\mathrm{PC}_{1 / 2}$ results from other sites for parasites with no pfk 13 mutant codons (Additional file 3: Figure S1). The mutant codon P574L predominated in that site. We tested the sensitivity of the association of codon P574L with slow clearance by including and excluding the site ID 15 data (Table 3 and Table 7). The association of the P574L codon with slow parasite clearance was highly significant in both analyses $(p \leq 0.001)$.
Data from three apparently relevant published studies were not shared [3, 22, 38]. However, the association of particular mutations with slow clearing parasites coincides with our analysis. In Southeast Asia, alleles Y493H, 539T, I543T, P553L, V568G, and C580Y in Thuy-Nhien et al. [22] and C580Y, Y493H, and R539T in Ariey et al. [3] were associated with slow clearance, and in Mali, the 9 pfk 13 mutant parasites identified by Ouattara et al. were not associated with slow clearance [38].

\section{Discussion}

This is the largest evaluation of the association of different pfk13 mutations with slow parasite clearance following antimalarial treatment with the artemisinin derivatives. 
Our study confirms that many, but not all (notably A578S), mutations in the propeller region of the pfk 13 gene are associated with slow parasite clearance. It also shows that a mutation outside the propeller region, E252Q which had been proposed to confer artemisinin resistance, is strongly associated with slow parasite clearance. This is also consistent with the increased prevalence for several years on the northwest ThailandMyanmar border of parasites that carried the E252Q mutation, presumably as a result of selection, before the ascendance of the C580Y genotype conferring a more extreme phenotype [18].

Several factors affect the rates of parasite clearance following administration of artemisinin derivatives and would have contributed to the inter-individual and between-site differences observed in this study. In infections with $p f k 13$ wild type parasites, treatment with an artemisinin derivative results in accelerated ring-form clearance, and this is reflected in a steep slope of the parasitemia-time profile and a derived $\mathrm{PC}_{1 / 2}$ which is usually well below $5.5 \mathrm{~h}$. Background immunity, or its surrogate, age has a significant additional effect, further accelerating parasite clearance. Thus, immunity as reflected by antibody concentrations can have a relatively small but significant effect [58]. Another important contributor to the half-life is the stage of parasite development at the initial presentation of the patient. This variable, too, could disproportionately affect clearance of pfk 13 mutant parasites compared to wild type infections [59] but should only affect inter-individual and not inter-site differences. In artemisinin combination treatments, the partner drug also makes a small contribution to the rate of parasite clearance, which in this study, was significant only for the mefloquine combination, confirming previous findings [60]. It is important to note that despite modest site-specific differences, the clearance half-life derived for each pf13 propeller alleles in the pooled data set was at least 1.5-fold higher than the half-life of the wild type parasites, and for 14 of the 20 propeller mutant alleles, the ratio of mutant to wild type $\mathrm{PC}_{1 / 2}$ was between 2.0 and 2.7 .

The prominent role of $p f k 13$ propeller mutants in the selective response to artemisinin drug pressure has been recently demonstrated by the rapid increase in parasites that carry a genotype with a particular version of the C580Y allele. These parasites originated in northwestern Cambodian and Thai foci and spread recently to new areas of Cambodia and Vietnam [22, 32]. On a more local scale, in this study, we found that the median $\mathrm{PC}_{1 / 2}$ of parasites that already carried a C580Y allele of $p f k 13$ increased from $5.4 \mathrm{~h}$ in 2009 to $7.2 \mathrm{~h}$ in 2014 in the western border region of Thailand. More widely, among the 14 pfk 13 propeller mutants newly associated with slow clearance, 4 of the 14 mutant alleles associated with slow clearance were present in at least $8 \%$ of the isolates identified in the corresponding parasite population (range 8-31\%). Ten of the newly identified pfk13 mutant alleles were present at low prevalence (range 1-6\%) in the sites where they have been reported and even among the validated alleles, prevalence was below $10 \%$ for four of the six alleles. Because the pooled data set contains isolates collected from many different sites and over a time span of 14 years, no trends in overall prevalence can be inferred in this analysis. However, the value of following temporal changes in the prevalence of propeller mutants in local sites is clear, as has been demonstrated for parasites that carry the C580Y allele in Thailand, Cambodia, and Vietnam [22, 32].

Detailed temporal studies $p f k 13$ mutant allele prevalence both in the GMS and in other worldwide sites represent a powerful tool for assessing whether a particular pfk13 mutant population is increasing, a signal that further studies of the parasite phenotype may be warranted in that location. Temporal studies will be particularly important for the seven newly identified propeller mutant alleles in our data set that were observed at prevalences of $4 \%$ or lower.

In contrast, the pfk 13 mutant parasites in all five African sites remained at very low prevalence, generally below 3\%, and no evidence of slow-clearing parasites or selection for mutant parasites has been identified. The low prevalence of $p f k 13$ mutant parasites in the African studies in our data set depends on relatively small numbers of parasites (e.g., 31, 26, 29). However, the generality of this observation is supported by extensive studies in many sites in Africa including some assessments of parasite clearance in vivo $[37,38,61-63]$, protection against parasite exposure to artemisinins of cultured parasites in vitro [10, 62, 64], and widespread molecular surveillance of $p f k 13$ propeller region sequence ([23-26, 55, 65-68] and see the WWARN K13 surveyor and WHO drug resistance threats map for details). These many reports also support the conclusions of our study: in African sites, pfk 13 propeller mutants are diverse but rare, with no evidence for selection even where artemisinin-based antimalarials have been intensively used. Moreover, the $p f k 13$ propeller mutant alleles commonly observed in Asia have rarely been observed in Africa $[40,69]$. In addition, only two African sites report a somewhat higher prevalence of parasites with $p f k 13$ propeller mutations, $14 \%(18 / 130)$ in Mali [23] and an increase from $3 \%(1 / 31)$ in 2007 to $27 \%(7 / 26)$ in 2014 in Grande Comoros [70] and 17\% (5/29) mutants in individuals from the neighboring island of Mayotte [71].

The $p f k 13$ gene has been identified as essential to $P$. falciparum in its blood stream stage [72], and it is likely that parasites dependent upon a mutant K13 protein would incur a considerable fitness disadvantage [64]. In this 
situation, parasite populations subjected to intensive use of artemisinin-based antimalarials would be expected to be under intense selection for $p f k 13$ mutant parasites that carry additional genetic changes that could compensate for the fitness cost as has been observed in other parasite populations under drug selection [73]. There is increasing evidence that such adaptive responses have evolved in Southeast Asian P. falciparum populations [74]. For example, intensive use of the ACT dihydroartemisininpiperaquine in Cambodia and Thailand has apparently exerted further selection on the parasites that carry the pfk 13 C580Y "spreading" genotype, selecting parasites that also carry an increased copy number of plasmepsin 2-3 that confers resistance to the piperaquine partner drug [33-35]. In addition to selection and spread of pfk13 mutant parasites, independent populations that carry new versions of the common C580Y or one of many novel pfk 13 alleles have emerged in many other sites within the GMS region [12-15, 21, 22, 28, 54].

Even before the $p f k 13$ gene was identified as a potential molecular marker of reduced artemisinin response, genome-wide association studies identified several regions of the $P$. falciparum genome associated with slow parasite clearance on chromosomes 10 and 14, in addition to chromosome 13 where the pfk 13 gene is located [5, 6, 75]. Whole genome analyses have also identified genetic changes associated both with $p f k 13$ propeller mutants and with slow clearance in independent, low diversity populations in Cambodia [76, 77] and in Western Thailand [78]. Parasites that carry these additional genetic changes are present in many populations in the western regions of Southeast Asia [21, 28, 79]. Moreover, the importance of other genetic changes for the expression of the slow clearance phenotype has been observed in vitro. Introduction of a pfk13 mutant allele into a cloned, fast-clearing wild type parasite of recent Cambodian origin conferred more protection against dihydroartemisinin in vitro than when the same allele was expressed in a wild type parasite line of African origin [10]. These observations support the interpretation that the independent emergence of parasite populations with new pfk 13 alleles is facilitated in Southeast Asia by the presence of local parasite populations with genomes already adapted to support $p k 13 \mathrm{mu}$ tant parasites when they arise. Exposure to artemisinins could then quite rapidly select emergence and selection of a local population of $p f k 13$ mutant parasites.

These specific adaptive genomic changes that are common in Southeast Asian parasites have not been observed in African isolates, but comprehensive analyses have not yet been undertaken [28]. The slow clearance phenotype is extremely complex, dependent on changes in the overall stress response to artemisinins (see $[80,81]$ for comprehensive reviews) and there may be many other combinations of adaptive genomic changes that could support the fitness of $p f k 13$ mutant parasites. In addition, it is clear that genetic changes other than $p f k 13$ mutations can confer diminished response to artemisinins in vitro and in vivo [82-85] and surveillance plans will need to remain open to the possibility of these alternative genetic strategies.

This meta-analysis still depends on detailed multiple quantitative assessments of the parasite count, not an approach that is likely to be feasible for routine surveillance in many study sites. This study highlights the limitations in sensitivity and specificity of the standard assessment of parasite clearance on day 3 as a phenotypic signal of delayed clearance. There is no question that simpler methods for assessment of parasite responses to artemisinins will be needed in all endemic areas, with particular attention to areas where malaria transmission is low and drug pressure will be most likely to select resistance.

Our large data set allowed identification of significant association of $p f k 13$ parasite genotype and $\mathrm{PC}_{1 / 2}$ phenotype even when the sample size of parasites with a particular allele was very small. For example, four different mutant alleles were observed in fewer than eight patient isolates. Even in these cases, the analysis allowed a strong genotype-phenotype association to be identified. Among these rare mutant alleles, the ratio of mutant to wild type $\mathrm{PC}_{1 / 2}$ ranged from 1.9 to 2.7 , ten of the mutant alleles are present in more than $10 \%$ of the parasites in the tested isolates, and all but four were observed in more than one study site. This robust outcome demonstrates that analyses of the $\mathrm{PC}_{1 / 2}$ in patients can allow identification of mutant $p f k 13$ alleles associated with slow-clearing parasites even when malaria transmission is low and few patients can be assessed. This suggests that some researchers in areas outside the GMS may be able to assess the $\mathrm{PC}_{1 / 2}$ phenotype in vivo $[11,37,38,61]$ or parasite responses to artemisinins in vitro [10,62, 85-87] as a screen for artemisinin response as some groups have already done.

Finally, 18 data sets were included in this meta-analysis of individual patient data sets, including 4 trials that had not yet been published. We believe that this demonstrates that the engagement of research groups to share individual patient data can provide a unique opportunity for advancement of public health. This approach can combine and facilitate collaborative analysis of critical data sets, defining outcomes that cannot be achieved by only extracting outcomes from multiple single publications. Such meta-analyses can provide evidence for policy makers, while not precluding subsequent individual study publications. 
There are limitations of this meta-analysis. Notably, the uneven representation of isolates derived from different sites of origin between Africa and Asia and within Southeast Asia and the imbalance of longitudinal data among the sites. The extensive long-term record of clinical outcomes of artemisinin treatment from patients on the Thai Western Border contributed many more isolates to the available data set than any other site $(1291 / 3087,42 \%)$. However, this rich sample set is itself diverse, contributing information on 31 of the 44 mutant alleles observed in the Asian data set. Moreover, the patients studied were not from a very limited area, but came from sites situated over an extended region of the northwest Thai/eastern Myanmar border. The diversity of propeller mutant genotypes supports the assumption that this large number of isolates from the Thai Western Border is representative of the Eastern part of the whole region that includes Thailand, Cambodia, Lao PDR, and Vietnam.

\section{Conclusions}

The slow clearance phenotype that has evolved in $P$. falciparum parasite populations in response to artemisinin challenge is complex and can involve at least one non-synonymous change in the $P$. falciparum-specific region of the $p f k 13$ gene, but most frequently, specific single mutations in the propeller region. These different propeller mutations may also compromise parasite fitness, so genomic studies that further define the other genomic changes in parasite populations that support pfk13 mutants to overcome fitness deficits will be needed.

Despite this complexity of the phenotype, the appearance and selection of mutations in the pfk 13 propeller region are valuable markers for surveillance of diminished artemisinin responsiveness in parasite populations. This meta-analysis demonstrates that 14 pfk 13 propeller mutants, in addition to the 6 previously validated, are associated with prolonged parasite clearance and could be considered for implementation as molecular markers in the Greater Mekong Subregion, as a potential early signal of slow parasite clearance.

The confirmation of the apparent absence outside of Southeast Asia of common pfk 13 alleles associated with slow clearance is welcome. However, testing of a more practical and sensitive protocol than persistence of parasites on day 3 that can be a first signal of prolonged parasite clearance is urgently needed. Such an approach should also include vigilance for diminished artemisinin responses signaled by increasing prevalence of parasites with mutant alleles of $p f k 13$ or of other genetic changes that may also diminish parasite responses to artemisinins.

\section{Additional files}

Additional file 1: Details of the systematic literature review. (PDF $213 \mathrm{~kb}$ )

Additional file 2: Supplementary Tables S1-S3. (XLSX $66 \mathrm{~kb}$ )

Additional file 3: Supplementary Figures S1- S9. (PDF 1168 kb)

\section{Abbreviations}

ACTs: Artemisinin combination therapies; AL: Artemether/lumefantrine; AS + ACT: Artesunate + artemisinin combination therapy; AS: Artesunate; ASAQ: Artesunate/amodiaquine; ASMQ: Artesunate/mefloquine; DHAPIP: Dihydroartemisinin/piperaquine; DMSAP: Data Management and Statistical Analysis Plan; FN: False negative; FP: False positive; GMS: Greater Mekong Subregion; NS: Non-synonymous; OxTREC: Oxford Tropical Research Ethics Committee; PC $_{1 / 2}$ : Parasite clearance half-life; PCE: Parasite clearance estimator tool; RSA: Ring-stage survival assay; TRAC: Tracking resistance to artemisinin collaboration; WHO: World Health Organization

\section{Acknowledgements}

We appreciate the careful review of the manuscript by Pascal Ringwald and the advice and contributions of Paul Newton and the Structural Genomics Consortium who have publically shared the data on the structure of the propeller region of the K13 protein. The members of the WorldWide Antimalarial Resistance Network (WWARN) K13 Genotype-Phenotype Correlation Study Group are the authors of this paper:

Chanaki Amaratunga

Laboratory of Malaria and Vector Research, Division of Intramural Research, National Institute of Allergy and Infectious Diseases, National Institutes of Health, Rockville, Maryland, USA

Voahangy Hanitriniaina Andrianaranjaka

Malaria Research Unit, Institut Pasteur de Madagascar, Antananarivo,

Madagascar, and Faculté des Sciences, Université d'Antananarivo,

Antananarivo, Madagascar

Elizabeth Ashley

Myanmar-Oxford Clinical Research Unit (MOCRU), Yangon, Myanmar, and Centre for Tropical Medicine and Global Health, University of Oxford, UK

Delia Bethell

Armed Forces Research Institute of Medical Sciences, Bangkok, Thailand Anders Björkman

Department of Molecular, Tumor, and Cell Biology, Karolinska Institutet, Stockholm, Sweden

Craig A. Bonnington

Shoklo Malaria Research Unit, Mae Sot, Thailand

Roland A. Cooper

Department of Natural Sciences and Mathematics, Dominican University of California, San Rafael, CA, USA

Mehul Dhorda

WWARN, Centre for Tropical Medicine, Nuffield Department of Clinical Medicine,University of Oxford, Oxford, UK

Arjen Dondorp

Mahidol-Oxford Research Unit, Faculty of Tropical Medicine, Mahidol University, Bangkok, Thailand, and WWARN, Centre for Tropical Medicine, Nuffield Department of Clinical Medicine, University of Oxford, Oxford, UK

Annette Erhart

Department of Public Health, ITM Antwerp, Belgium, and Institute of Tropical Medicine, MRC Unit The Gambia, Fajara, Gambia

Rick M. Fairhurst

Laboratory of Malaria and Vector Research, Division of Intramural Research, National Institute of Allergy and Infectious Diseases, National Institutes of Health, Rockville, Maryland, USA

Abul Faiz

Dev Care Foundation, Dhaka, Bangladesh

Caterina Fanello

Centre for Tropical Medicine, Nuffield Department of Clinical

Medicine,University of Oxford, Oxford, UK, and Mahidol-Oxford Research Unit, Bangkok, Thailand

Mark M. Fukuda

Armed Forces Research Institute of Medical Sciences, Bangkok, Thailand Philippe Guérin 
WWARN, Centre for Tropical Medicine, Nuffield Department of Clinical Medicine, University of Oxford, Oxford, UK

Rob Hooft van Huijsduijnen

Medicines for Malaria Venture, Meyrin, Geneva, Switzerland

Tran Tinh Hien

Centre for Tropical Medicine Oxford University, Clinical Research Unit, Ho Chi Minh City, Vietnam

\section{NV Hong}

National Institute of Malariology, Parasitology and Entomology, Hanoi, Vietnam

Ye Htut

Department of Medical Research, Lower Myanmar, Yangon, Myanmar

\section{Fang Huang}

National Institute of Parasitic Diseases, Chinese Center for Disease Control and Prevention, Shanghai, China

Georgina Humphreys

WWARN, Centre for Tropical Medicine, Nuffield Department of Clinical Medicine,University of Oxford, Oxford, UK

\section{Mallika Imwong}

Department of Molecular Tropical Medicine and Genetics Faculty of Tropical Medicine, Mahidol University, Bangkok, Thailand and MahidolOxford Tropical Medicine Research Unit, Faculty of Tropical Medicine, Mahidol University, Bangkok, Thailand

Kalynn Kennon

WWARN, Centre for Tropical Medicine, Nuffield Department of Clinical Medicine,University of Oxford, Oxford,UK

\section{Pharath Lim}

Laboratory of Malaria and Vector Research, Division of Intramural Research, National Institute of Allergy and Infectious Diseases, National Institutes of Health, Rockville, Maryland, USA

Khin Lin

Department of Medical Research, (PYIN OO LWIN BRANCH), Myanmar

Chanthap Lon

Armed Forces Research Institute of Medical Sciences, Bangkok, Thailand

\section{Andreas Mårtensson}

Department of Women's and Children's Health, International Maternal and Child health (IMCH) Uppsala University, Uppsala, Sweden

\section{Mayfong Mayxay}

Lao-Oxford-Mahosot Hospital-Wellcome Trust Research Unit (LOMWRU), Vientiane, Lao PDR, and Faculty of Postgraduate Studies, University of Health Sciences, Ministry of Health, Vientiane, Lao PDR, and Centre for Tropical Medicine and Global Health, Nuffield Department of Medicine, Churchill Hospital, Oxford, UK

\section{Olugbenga Mokuolu}

Department of Paediatrics and Child Health, College of Health Sciences, University of llorin, llorin, Nigeria, and Centre for Malaria and Other Tropical Diseases Care, University of Ilorin Teaching Hospital, Ilorin, Nigeria

\section{Ulrika Morris}

Department of Molecular, Tumor, and Cell Biology, Karolinska Institutet, Stockholm, Sweden

Billy E. Ngasala

Department of Parasitology and Medical Entomology, Muhimbili University of Health and Allied Sciences, Dar es Salaam, Tanzania

Alfred Amambua-Ngwa

Institute of Tropical Medicine, MRC Unit The Gambia, Fajara, Gambia

Harald Noedl

Institute of Specific Prophylaxis and Tropical Medicine, Medical University of Vienna, Vienna, Austria

\section{François Nosten}

Shoklo Malaria Research Unit, Mae Sot, Thailand, Mahidol-Oxford Tropical Medicine Research Unit, Faculty of Tropical Medicine, Mahidol University, Bangkok, Thailand, and Centre for Tropical Medicine, Nuffield Department of Clinical Medicine, University of Oxford, Oxford, UK

\section{Marie Onyamboko}

Kinshasa School of Public Health, Kinshasa, DRC and Mahidol-Oxford Research Unit, Bangkok, Thailand

Aung Pyae Phyo

Shoklo Malaria Research Unit, Mae Sot, Thailand, Mahidol-Oxford Tropical Medicine Research Unit, Faculty of Tropical Medicine, Mahidol University, Bangkok, Thailand and Centre for Tropical Medicine, Nuffield Department of Clinical Medicine, University of Oxford, Oxford, UK

Christopher V. Plowe
Duke Global Health Institute, Duke University, Durham, NC, USA

Sasithon Pukrittayakamee

Department of Clinical Tropical Medicine, Mahidol University, Bangkok, Thailand and Royal Society of Thailand, Sanam Suea Pa, Khet Dusit, Bangkok, Thailand

Milijaona Randrianarivelojosia

Malaria Research Unit, Institut Pasteur de Madagascar, Antananarivo,

Madagascar and Faculté des Sciences, Université de Toliara, Toliara, Madagascar

Philip J. Rosenthal

Department of Medicine and Division of HIV, Infectious Diseases, and Global Medicine, University of California, San Francisco, San Francisco, CA, USA

David L. Saunders

Armed Forces Research Institute of Regenerative Medicine, Bangkok, Thailand and US Army Medical Materiel Development Activity, Fort Detrick, Maryland, USA

\section{Carol Hopkins Sibley}

Department of Genome Sciences, University of Washington, Seattle, WA USA and WWARN, Centre for Tropical Medicine, Nuffield Department of Clinical Medicine, University of Oxford, Oxford, UK

Frank Smithuis

Myanmar Oxford Clinical Research Unit, Yangon, Myanmar

\section{Michele D. Spring}

Department of Immunology and Medicine, Armed Forces Research Institute of Medical Sciences, Bangkok, Thailand

\section{Paul Sondo}

WWARN, Centre for Tropical Medicine, Nuffield Department of Clinical Medicine,University of Oxford, Oxford, UK and Clinical Research Unit of Nanoro (CRUN), Burkina Faso

Sokunthea Sreng

National Center for Parasitology, Entomology and Malaria Control, Phnom Penh, Cambodia

Peter Starzengruber

Institute of Specific Prophylaxis and Tropical Medicine, Medical University of Vienna, Vienna, Austria and Division of Clinical Microbiology, Department of Laboratory Medicine, Medical University of Vienna, Vienna, Austria

Kasia Stepniewska

WWARN, Centre for Tropical Medicine and Global Health, University of Oxford, Oxford, UK

Seila Suon

National Center for Parasitology, Entomology and Malaria Control, Phnom Penh, Cambodia

\section{Shannon Takala-Harrison}

Division of Malaria Research, Institute for Global Health, University of Maryland School of Medicine, Baltimore, MD, USA

\section{Kamala Thriemer}

Institute of Tropical Medicine, Antwerp, Belgium and Menzies School of Health Research, Darwin, Australia

Nguyen Thuy-Nhien

Centre for Tropical Medicine Oxford University Clinical Research Unit. Ho Chi Minh City, Vietnam

Kyaw Myo Tun

Defense Services Medical Academy, Yangon, Myanmar and MyanmarOxford Clinical Research Unit, Yangon, Myanmar

\section{Nicholas J. White}

Mahidol-Oxford Research Unit, Faculty of Tropical Medicine, Mahidol University, Bangkok, Thailand and Centre for Tropical Medicine, Nuffield Department of Clinical Medicine, University of Oxford, Oxford, UK

\section{Charles Woodrow}

Mahidol-Oxford Research Unit, Faculty of Tropical Medicine, Mahidol University, Bangkok,Thailand and Centre for Tropical Medicine, Nuffield Department of Clinical Medicine, University of Oxford, Oxford, UK

\section{Funding}

This pooled analysis was funded by grants from the ExxonMobil Foundation and the Bill \& Melinda Gates Foundation. Funders had no input on the planning, analysis, or presentation of the study. Information on funding support for the primary data collection and analysis can be found in the respective referenced manuscripts; these publications are also listed in Additional file 2. Table $\$ 1$.

\section{Data access}

The data are available for access via the WorldWide Antimalarial Resistance Network (WWARN.org). Requests for access will be reviewed by a Data 
Access Committee to ensure that use of data protects the interests of the participants and researchers according to the WWARN principles of data sharing (WWARN.org/tools-resources/terms-data-access). Requests can be submitted by email to malariaDAC@iddo.org via the Data Access Form available at WWARN.org/accessing-data. WWARN is registered with the Registry of Research Data Repositories (re3data.org).

\section{Authors' contributions}

$\mathrm{KS}, \mathrm{CHS}, \mathrm{PG}, \mathrm{NJW}, \mathrm{MD}, \mathrm{EA}$, and FN conceived/designed the meta-analysis. NJW, EA, AB, MD, MI, AE, RAC, PJR, AAN, RMF, AM, UM, HN, FN, APP, MR, DLS, $\mathrm{KT}$, and $\mathrm{KMT}$ conceived/designed the original experiments. CHS and KS wrote the first draft. KS, CHS, PG, NJW, PJR, AB, EA, CVP, MD, RAC, CA, KT, DB, $R M F, A E, F H, R H H, S T H, K K$, and P Sondo contributed to the writing of the manuscript. EA, AB, AAN, RMF, AM, UM, HN, FN, MI, APP, MR, DLS, KT, KMT, $C A, V H A, D B, C A B, M D, A E, A F, C F, M M F, R H H, T T H, N V H, Y H, F H, C L, M M, O M$, BEN, MO, CVP, SP, MDS, P Starzengruber, STH, NTN, CW, S Sreng, and S Suon contributed the reagents, data, or materials. EA, AB, RMF, AM, UM, FN, APP, $M R, D L S, K T, K M T, C A, V H A, D B, C A B, A E, A F, C F, M M F, N V H, Y H, F H, C L, M M$ OM, BEN, MO, SP, MDS, NTN, S Sreng, and S Suon enrolled patients/performed experiments. EA, AAN, MI, RMF, CA, PL, FN, FH, APP, NTN, and CW analyzed the data in original studies. $\mathrm{KS}, \mathrm{CHS}, \mathrm{PG}, \mathrm{KK}$, P Sondo, and $\mathrm{GH}$ performed the IPD meta-analysis. All authors read and approved the manuscript.

\section{Ethics approval and consent to participate}

All data included in this analysis were obtained from studies conducted with ethical approvals from the country of origin. Use of existing data which are fully anonymized and which researchers cannot trace back to identifiable individuals does not require the review of the Ethics Committee under the guidelines of the Oxford Central University Research Ethics Committee.

\section{Consent for publication}

Not required

\section{Competing interests}

The authors declare that they have no competing interests.

\section{Publisher's Note}

Springer Nature remains neutral with regard to jurisdictional claims in published maps and institutional affiliations.

\section{Received: 7 June 2018 Accepted: 1 November 2018}

\section{Published online: 17 January 2019}

\section{References}

1. Noedl H, Se Y, Schaecher K, Smith BL, Socheat D, Fukuda MM. Evidence of artemisinin-resistant malaria in western Cambodia. New Eng J Med. 2008; 359(24):2619-20.

2. Dondorp AM, Nosten F, Yi P, Das D, Phyo AP, Tarning J, Lwin KM, Ariey F, Hanpithakpong W, Lee SJ, et al. Artemisinin resistance in Plasmodium falciparum malaria. New Eng J Med. 2009;361(5):455-67.

3. Ariey F, Witkowski B, Amaratunga C, Beghain J, Langlois A-C, Khim N, Kim S, Duru V, Bouchier C, Ma L, et al. A molecular marker of artemisinin-resistant Plasmodium falciparum malaria. Nature. 2014;505(7481):50-5.

4. Plowe CV. Malaria: resistance nailed. Nature. 2014:505(7481):30-1.

5. Cheeseman $\mathrm{IH}$, Miller BA, Nair S, Nkhoma S, Tan A, Tan JC, Al Saai S, Phyo $A P$, Moo CL, Lwin KM, et al. A major genome region underlying artemisinin resistance in malaria. Science. 2012;336(6077):79-82.

6. Takala-Harrison S, Clark TG, Jacob CG, Cummings MP, Miotto O, Dondorp AM, Fukuda MM, Nosten F, Noedl H, Imwong M, et al. Genetic loci associated with delayed clearance of Plasmodium falciparum following artemisinin treatment in Southeast Asia. Proc Nat Acad Sci U S A. 2013; 110(1):240-5.

7. Witkowski B, Amaratunga C, Khim N, Sreng S, Chim P, Kim S, Lim P, Mao S, Sopha C, Sam B, et al. Novel phenotypic assays for the detection of artemisinin-resistant Plasmodium falciparum malaria in Cambodia: in-vitro and ex-vivo drug-response studies. Lancet Infect Dis. 2013;13(12):1043-9.

8. Chotivanich K, Tripura R, Das D, Yi P, Day NPJ, Pukrittayakamee S, Chuor CM, Socheat D, Dondorp AM, White NJ. Laboratory detection of artemisininresistant Plasmodium falciparum. Antimicrob Agents Chemother. 2014;58(6): 3157-61.
9. 4YY8: crystal structure analysis of Kelch protein from Plasmodium falciparum [http://www.rcsb.org/pdb/explore.do?structureld=4yy8] Accessed 25 June 2018.

10. Straimer J, Gnadig NF, Witkowski B, Amaratunga C, Duru V, Ramadani AP, Dacheux M, Khim N, Zhang L, Lam S, et al. Drug resistance. K13-propeller mutations confer artemisinin resistance in Plasmodium falciparum clinical isolates. Science. 2015;347(6220):428-31.

11. Ashley EA, Dhorda M, Fairhurst RM, Amaratunga C, Lim P, Suon S, Sreng $S$, Anderson JM, Mao S, Sam B, et al. Spread of artemisinin resistance in Plasmodium falciparum malaria. New Eng J Med. 2014;371(5):411-23.

12. Nyunt MH, Hlaing T, Oo HW, Tin-Oo LL, Phway HP, Wang B, Zaw NN, Han SS, Tun T, San KK, et al. Molecular assessment of artemisinin resistance markers, polymorphisms in the k13 propeller, and a multidrug-resistance gene in the eastern and western border areas of Myanmar. Clin Infect Dis. 2015;60(8):1208-15.

13. Tun KM, Imwong $M$, Lwin KM, Win AA, Hlaing TM, Hlaing $T$, Lin $K$, Kyaw MP, Plewes K, Faiz MA, et al. Spread of artemisinin-resistant Plasmodium falciparum in Myanmar: a cross-sectional survey of the K13 molecular marker. Lancet Infect Dis. 2015;15(4):415-21.

14. Wang Z, Wang Y, Cabrera M, Zhang Y, Gupta B, Wu Y, Kemirembe K, Hu Y, Liang $X$, Brashear $A$, et al. Artemisinin resistance at the China-Myanmar border and association with mutations in the K13 propeller gene. Antimicrob Agents Chemother. 2015;59(11):6952-9.

15. Takala-Harrison S, Jacob CG, Arze C, Cummings MP, Silva JC, Dondorp AM, Fukuda MM, Hien TT, Mayxay M, Noedl H, et al. Independent emergence of artemisinin resistance mutations among Plasmodium falciparum in Southeast Asia. J Infect Dis. 2015;211(5):670-9.

16. Huang F, Takala-Harrison S, Jacob CG, Liu H, Sun X, Yang H, Nyunt MM, Adams M, Zhou S, Xia Z, et al. A single mutation in K13 predominates in southern China and is associated with delayed clearance of Plasmodium falciparum following artemisinin treatment. J Infect Dis. 2015;212(10):1629-35.

17. Ye R, Hu D, Zhang Y, Huang Y, Sun X, Wang J, Chen X, Zhou H, Zhang D, Mungthin $\mathrm{M}$, et al. Distinctive origin of artemisinin-resistant Plasmodium falciparum on the China-Myanmar border. SciRep. 2016:6:20100.

18. Phyo AP, Ashley EA, Anderson TJC, Bozdech Z, Carrara VI, Sriprawat K, Nair S, White MM, Dziekan J, Ling C, et al. Declining efficacy of artemisinin combination therapy against $P$. falciparum malaria on the Thai-Myanmar Border (2003-2013): the role of parasite genetic factors. Clin Infect Dis. 2016; 63(6):784-91.

19. Bonnington CA, Phyo AP, Ashley EA, Imwong M, Sriprawat K, Parker DM, Proux S, White NJ, Nosten F. Plasmodium falciparum Kelch 13 mutations and treatment response in patients in Hpa-Pun District, Northern Kayin State, Myanmar. Malar J. 2017;16(1):480.

20. Myint MK, Rasmussen C, Thi A, Bustos D, Ringwald P, Lin K. Therapeutic efficacy and artemisinin resistance in northern Myanmar: evidence from in vivo and molecular marker studies. Malar J. 2017;16(1):143.

21. Nyunt MH, Soe MT, Myint HW, Oo HW, Aye MM, Han SS, Zaw NN, Cho C, Aung PZ, Kyaw KT, et al. Clinical and molecular surveillance of artemisinin resistant falciparum malaria in Myanmar (2009-2013). Malar J. 2017;16(1):333.

22. Thuy-Nhien N, Tuyen NK, Tong NT, Vy NT, Thanh NV, Van HT, Huong-Thu P, Quang HH, Boni MF, Dolecek C, et al. K13 propeller mutations in Plasmodium falciparum populations in regions of malaria endemicity in Vietnam from 2009 to 2016. Antimicrob Agents Chemother. 2017;61(4): e01578-01516

23. Taylor SM, Parobek CM, DeConti DK, Kayentao K, Coulibaly SO, Greenwood BM, Tagbor H, Williams J, Bojang K, Njie F, et al. Absence of putative artemisinin resistance mutations among Plasmodium falciparum in subSaharan Africa: a molecular epidemiologic study. J Infect Dis. 2015;211(5): 680-8.

24. Kamau E, Campino S, Amenga-Etego L, Drury E, Ishengoma D, Johnson K, Mumba D, Kekre M, Yavo W, Mead D, et al. K13-propeller polymorphisms in Plasmodium falciparum parasites from sub-Saharan Africa. J Infect Dis. 2015; 211(8):1352-5

25. Talundzic E, Ndiaye YD, Deme AB, Olsen C, Patel DS, Biliya S, Daniels R, Vannberg FO, Volkman SK, Udhayakumar V, et al. Molecular epidemiology of Plasmodium falciparum kelch13 mutations in senegal determined by using targeted amplicon deep sequencing. Antimicrob Agents Chemother. 2017; 61(3):e02116.

26. Mvumbi DM, Bobanga TL, Kayembe J-MN, Mvumbi GL, Situakibanza HN-T, Benoit-Vical F, Melin P, De Mol P, Hayette M-P. Molecular surveillance of Plasmodium falciparum resistance to artemisinin-based combination 
therapies in the Democratic Republic of Congo. PLoS One. 2017;12(6): e0179142.

27. Menard D, Khim N, Beghain J, Adegnika AA, Shafiul-Alam M, Amodu O, Rahim-Awab G, Barnadas C, Berry A, Boum Y, et al. A worldwide map of Plasmodium falciparum K13-propeller polymorphisms. New Eng J Med. 2016; 374(25):2453-64

28. MalariaGEN. Genomic epidemiology of artemisinin resistant malaria. eLife. 2016:5:e08714.

29. Stepniewska K, Ashley E, Lee SJ, Anstey N, Barnes Kl, Binh TQ, D'Alessandro U, Day NP, de Vries PJ, Dorsey G, et al. In vivo parasitological measures of artemisinin susceptibility. J Infect Dis. 2010;201(4):570-9.

30. Flegg JA, Guerin PJ, White NJ, Stepniewska K. Standardizing the measurement of parasite clearance in falciparum malaria: the parasite clearance estimator. Malar J. 2011;10:339.

31. Nkhoma SC, Stepniewska K, Nair S, Phyo AP, McGready R, Nosten F, Anderson TJ. Genetic evaluation of the performance of malaria parasite clearance rate metrics. J Infect Dis. 2013;208(2):346-50.

32. Imwong M, Suwannasin K, Kunasol C, Sutawong K, Mayxay M, Rekol H, Smithuis FM, Hlaing TM, Tun KM, van der Pluijm RW, et al. The spread of artemisininresistant Plasmodium falciparum in the Greater Mekong subregion: a molecular epidemiology observational study. Lancet Infect Dis. 2017;17(5):491-7.

33. Amato R, Lim P, Miotto O, Amaratunga C, Dek D, Pearson RD, AlmagroGarcia J, Neal AT, Sreng S, Suon S, et al. Genetic markers associated with dihydroartemisinin-piperaquine failure in Plasmodium falciparum malaria in Cambodia: a genotype-phenotype association study. Lancet Infect Dis. 2017; 17(2):164-73.

34. Imwong M, Hien TT, Thuy-Nhien NT, Dondorp AM, White NJ. Spread of a single multidrug resistant malaria parasite lineage (PfPailin) to Vietnam. Lancet Infect Dis. 2017;17(10):1022-3.

35. Amato R, Pearson RD, Almagro-Garcia J, Amaratunga C, Lim P, Suon S, Sreng S, Drury E, Stalker J, Miotto O, et al. Origins of the current outbreak of multidrug-resistant malaria in Southeast Asia: a retrospective genetic study. Lancet Infect Dis. 2018;18(3):337-45.

36. Conrad MD, Bigira V, Kapisi J, Muhindo M, Kamya MR, Havlir DV, Dorsey G, Rosenthal PJ. Polymorphisms in K13 and falcipain-2 associated with artemisinin resistance are not prevalent in Plasmodium falciparum isolated from Ugandan children. PLoS One. 2014;9(8):e105690.

37. Maiga AW, Fofana B, Sagara I, Dembele D, Dara A, Traore OB, Toure S, Sanogo K, Dama S, Sidibe B, et al. No evidence of delayed parasite clearance after oral artesunate treatment of uncomplicated falciparum malaria in Mali. Am J Trop Med Hyg. 2012;87(1):23-8.

38. Ouattara A, Kone A, Adams M, Fofana B, Maiga AW, Hampton S, Coulibaly D, Thera MA, Diallo N, Dara A, et al. Polymorphisms in the K13-propeller gene in artemisinin-susceptible Plasmodium falciparum parasites from BougoulaHameau and Bandiagara, Mali. Am J Trop Med Hye. 2015;92(6):1202-6.

39. Chenet SM, Akinyi Okoth S, Huber CS, Chandrabose J, Lucchi NW, Talundzic E, Krishnalall K, Ceron N, Musset L, Macedo de Oliveira A, et al. Independent emergence of the Plasmodium falciparum Kelch propeller domain mutant allele C580Y in Guyana. J Infect Dis. 2016;213(9):1472-5.

40. Tacoli C, Gai PP, Bayingana C, Sifft K, Geus D, Ndoli J, Sendegeya A, Gahutu JB, Mockenhaupt FP. Artemisinin resistance-associated K13 polymorphisms of Plasmodium falciparum in southern Rwanda, 2010-2015. Am J Trop Med Hyg. 2016;95(5):1090-3.

41. Flegg JA, Guerin PJ, Nosten F, Ashley EA, Phyo AP, Dondorp AM, Fairhurst RM, Socheat D, Borrmann S, Bjorkman A, et al. Optimal sampling designs for estimation of Plasmodium falciparum clearance rates in patients treated with artemisinin derivatives. Malar J. 2013;12:411.

42. Artemisinin and artemisinin-based combination therapy resistance [http:// apps.who.int/iris/bitstream/10665/255213/1/WHO-HTM-GMP-2017.9-eng. pdf?ua=1] Accessed 12 June 2018.

43. Stewart LA, Clarke M, Rovers M, Riley RD, Simmonds M, Stewart G, Tierney JF, Group P-ID. Preferred reporting items for systematic review and metaanalyses of individual participant data: the PRISMA-IPD statement. JAMA. 2015;313(16):1657-65.

44. Bethell D, Se Y, Lon C, Tyner S, Saunders D, Sriwichai S, Darapiseth S, Teja-Isavadharm P, Khemawoot P, Schaecher K, et al. Artesunate dose escalation for the treatment of uncomplicated malaria in a region of reported artemisinin resistance: a randomized clinical trial. PLoS One. 2011;6(5):e19283.

45. Das D, Tripura R, Phyo AP, Lwin KM, Tarning J, Lee SJ, Hanpithakpong W, Stepniewska K, Menard D, Ringwald P, et al. Effect of high-dose or split-dose artesunate on parasite clearance in artemisinin-resistant falciparum malaria. Clin Infect Dis. 2013;56(5):e48-58.

46. Hien T, Thuy-Nhien N, Phu N, Boni M, Thanh N, Nha-Ca N, Thai L, Thai C, Toi $P$, Thuan $P$, et al. In vivo susceptibility of Plasmodium falciparum to artesunate in Binh Phuoc Province, Vietnam. Malar J. 2012;11(1):355.

47. Mayxay M, Khanthavong M, Chanthongthip O, Imwong M, Lee S, Stepniewska K, Soonthornsata B, Pongvongsa T, Phompida S, Hongvanthong B, et al. No evidence for spread of Plasmodium falciparum artemisinin resistance to Savannakhet Province, southern Laos. Am J Trop Med Hyg. 2012;86(3):403-8.

48. Phyo AP, Nkhoma S, Stepniewska K, Ashley EA, Nair S, McGready R, ler Moo C, Al-Saai S, Dondorp AM, Lwin KM, et al. Emergence of artemisinin-resistant malaria on the western border of Thailand: a longitudinal study. Lancet. 2012;379(9830):1960-6.

49. Starzengruber P, Swoboda P, Fuehrer HP, Khan WA, Hofecker V, Siedl A, Fally M, Graf O, Teja-Isavadharm P, Haque R, et al. Current status of artemisinin-resistant falciparum malaria in South Asia: a randomized controlled artesunate monotherapy trial in Bangladesh. PLoS One. 2012; 7(12):e52236.

50. Thriemer K, Hong NV, Rosanas-Urgell A, Phuc BQ, Ha do M, Pockele E, Guetens P, Van NV, Duong TT, Amambua-Ngwa A et al: Delayed parasite clearance after treatment with dihydroartemisinin-piperaquine in Plasmodium falciparum malaria patients in central Vietnam. Antimicrob Agents Chemother 2014, 58(12):7049-7055.

51. Tun KM, Jeeyapant A, Imwong M, Thein M, Aung SSM, Hlaing TM, Yuentrakul P, Promnarate C, Dhorda M, Woodrow CJ, et al. Parasite clearance rates in Upper Myanmar indicate a distinctive artemisinin resistance phenotype: a therapeutic efficacy study. Malar J. 2016;15(1):185.

52. Clinical module: data management and statistical analysis plan version 1.2 [www.wwarn.org/tools-resources/clinical-data-management-and-analysisplan] Accessed 3 June 2018.

53. Correlation between K13 mutations and phenotype study group Statistical Analysis Plan Version 1.0. [http://www.wwarn.org/tools-resources/k13-andclinical-phenotype-study-group-statistical-analysis-plan] Accessed 12 Jan 2018.

54. Talundzic E, Okoth SA, Congpuong K, Plucinski MM, Morton L, Goldman IF, Kachur PS, Wongsrichanalai C, Satimai W, Barnwell JW, et al. Selection and spread of artemisinin-resistant alleles in Thailand prior to the global artemisinin resistance containment campaign. PLoS Path. 2015;11(4):e1004789.

55. Kobasa T, Talundzic E, Sug-aram R, Boondat P, Goldman IF, Lucchi NW, Dharmarak P, Sintasath D, Fukuda M, Whistler T, et al. Emergence and spread of kelch13 mutations associated with artemisinin resistance in Plasmodium falciparum parasites in 12 Thai provinces from 2007 to 2016. Antimicrob Agents Chemother. 2018;62(4)::02141-02117.

56. WHO, editor. Methods and techniques for assessing exposure to antimalarial drugs in clinical field studies. Geneva: World Health Organization; 2011.

57. WHO: artemisinin resistance and artemisinin-based combination therapy efficacy. [http://apps.who.int/iris/bitstream/handle/10665/274362/WHO-CDSGMP-2018.18-eng.pdf?sequence=1\&isAllowed=y] accessed Nov 26, 2018.

58. Ataide R, Ashley EA, Powell R, Chan J-A, Malloy MJ, O'Flaherty K, Takashima E, Langer C, Tsuboi T, Dondorp AM, et al. Host immunity to Plasmodium falciparum and the assessment of emerging artemisinin resistance in a multinational cohort. Proc Natl Acad Sci U S A. 2017; 114(13):3515-20.

59. White N. The parasite clearance curve. Malar J. 2011;10(1):278.

60. Alin MH, Ashton M, Kihamia CM, Mtey GJ, Bjorkman A. Clinical efficacy and pharmacokinetics of artemisinin monotherapy and in combination with mefloquine in patients with falciparum malaria. Br J Clin Pharmacol. 1996; 41(6):587-92.

61. Lopera-Mesa TM, Doumbia S, Chiang S, Zeituni AE, Konate DS, Doumbouya M, Keita AS, Stepniewska K, Traore K, Diakite SA, et al. Plasmodium falciparum clearance rates in response to artesunate in Malian children with malaria: effect of acquired immunity. J Infect Dis. 2013;207(11):1655-63.

62. Cooper RA, Conrad MD, Watson QD, Huezo SJ, Ninsiima H, Tumwebaze P, Nsobya SL, Rosenthal PJ. Lack of artemisinin resistance in Plasmodium falciparum in Uganda based on parasitological and molecular assays. Antimicrob Agents Chemother. 2015;59(8):5061-4.

63. Sissoko S, Kone A, Fofana B, Sangaré C, Dembele D, Toure S, Sanogo K, Diakite H, Toure S, Doumbia D, et al. PF3D7_1343700 Kelch propeller (K13-propeller) polymorphisms and artesunate monotherapy efficacy in uncomplicated malaria treatment in Mali. BMJ Global Health. 2017; 2(Suppl 2):A18. 
64. Straimer J, Gnädig NF, Stokes BH, Ehrenberger M, Crane AA, Fidock DA. Plasmodium falciparum K13 mutations differentially impact ozonide susceptibility and parasite fitness in vitro. mBio. 2017;8(2):e00303-17.

65. Menegon M, Nurahmed AM, Talha AA, Nour BYM, Severini C. Molecular surveillance of antimalarial drug resistance related genes in Plasmodium falciparum isolates from Eritrea. Acta Trop. 2016;157:158-61.

66. Muwanguzi J, Henriques G, Sawa P, Bousema T, Sutherland CJ, Beshir KB. Lack of K13 mutations in Plasmodium falciparum persisting after artemisinin combination therapy treatment of Kenyan children. Malar J. 2016;15(1):36.

67. Guerra M, Neres R, Salqueiro P, Mendes C, Ndong-Mabale N, Berzosa P, de Sousa B, Arez AP. Plasmodium falciparum genetic diversity in continental Equatorial Guinea before and after introduction of artemisinin-based combination therapy. Antimicrob Agents Chemother. 2017;61(1):e00303-17.

68. Ljolje D, Dimbu PR, Kelley J, Goldman I, Nace D, Macaia A, Halsey ES, Ringwald P, Fortes F, Udhayakumar $V$, et al. Prevalence of molecular markers of artemisinin and lumefantrine resistance among patients with uncomplicated Plasmodium falciparum malaria in three provinces in Angola, 2015. Malar J. 2018;17(1):84.

69. Ocan M, Bwanga F, Okeng A, Katabazi F, Kigozi E, Kyobe S, Ogwal-Okeng J, Obua C. Prevalence of K13-propeller gene polymorphisms among Plasmodium falciparum parasites isolated from adult symptomatic patients in northern Uganda. BMC Infect Dis. 2016;16(1):428.

70. Huang B, Deng C, Yang T, Xue L, Wang Q, Huang S, Su XZ, Liu Y, Zheng S, Guan $Y$, et al. Polymorphisms of the artemisinin resistant marker (K13) in Plasmodium falciparum parasite populations of Grande Comore Island 10 years after artemisinin combination therapy. Parasit Vectors. 2015;8:634.

71. Torrentino-Madamet M, Collet L, Lepère JF, Benoit N, Amalvict R, Ménard D, Pradines B. K13-propeller polymorphisms in Plasmodium falciparum isolates from patients in Mayotte in 2013 and 2014. Antimicrob Agents Chemother. 2015;59(12):7878-81.

72. Zhang M, Wang C, Otto TD, Oberstaller J, Liao X, Adapa SR, Udenze K, Bronner IF, Casandra D, Mayho M, et al. Uncovering the essential genes of the human malaria parasite Plasmodium falciparum by saturation mutagenesis. Science. 2018;360(6388): eaap7847.

73. Jiang H, Patel JJ, Yi M, Mu J, Ding J, Stephens R, Cooper RA, Ferdig MT, Su X-Z. Genome-wide compensatory changes accompany drug-selected mutations in the Plasmodium falciparum crt gene. PLoS One. 2008;3(6):e2484.

74. Kümpornsin $\mathrm{K}$, Modchang $\mathrm{C}$, Heinberg $\mathrm{A}$, Ekland $\mathrm{EH}$, Jirawatcharadech $\mathrm{P}$ Chobson P, Suwanakitti N, Chaotheing S, Wilairat P, Deitsch KW, et al. Origin of robustness in generating drug-resistant malaria parasites. Mol Biol Evol. 2014;31(7):1649-60.

75. Cheeseman $\mathbb{H}$, McDew-White M, Phyo AP, Sriprawat K, Nosten F, Anderson TJC. Pooled sequencing and rare variant association tests for identifying the determinants of emerging drug resistance in malaria parasites. Mol Biol Evol. 2015;32(4):1080-90.

76. Miotto O, Amato R, Ashley EA, Maclnnis B, Almagro-Garcia J, Amaratunga C, Lim P, Mead D, Oyola SO, Dhorda M, et al. Genetic architecture of artemisinin-resistant Plasmodium falciparum. Nat Genet. 2015;47(3):226-34.

77. Dwivedi A, Reynes C, Kuehn A, Roche DB, Khim N, Hebrard M, Milanesi S, Rivals E, Frutos R, Menard D, et al. Functional analysis of Plasmodium falciparum subpopulations associated with artemisinin resistance in Cambodia. Malar J. 2017;16(1):493.

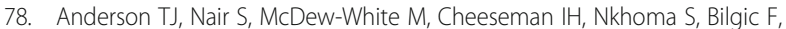
McGready R, Ashley E, Pyae Phyo A, White NJ, et al. Population parameters underlying an ongoing soft sweep in southeast Asian malaria parasites. Mol Biol Evol. 2017;34(1):131-44.

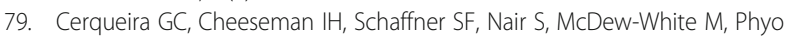
AP, Ashley EA, Melnikov A, Rogov P, Birren BW, et al. Longitudinal genomic surveillance of Plasmodium falciparum malaria parasites reveals complex genomic architecture of emerging artemisinin resistance. Genome Biol. 2017; 18(1):78

80. Tilley L, Straimer J, Gnadig NF, Ralph SA, Fidock DA. Artemisinin action and resistance in Plasmodium falciparum. Trends Parasitol. 2016;32(9):682-96.

81. Mok S, Ashley EA, Ferreira PE, Zhu L, Lin Z, Yeo T, Chotivanich K, Imwong M, Pukrittayakamee S, Dhorda M, et al. Drug resistance. Population transcriptomics of human malaria parasites reveals the mechanism of artemisinin resistance. Science. 2015;347(6220):431-5.

82. Mbengue A, Bhattacharjee S, Pandharkar T, Liu H, Estiu G, Stahelin RV, Rizk SS, Njimoh DL, Ryan Y, Chotivanich K, et al. A molecular mechanism of artemisinin resistance in Plasmodium falciparum malaria. Nature. 2015; 520(7549):683-7.
83. Mukherjee A, Bopp S, Magistrado P, Wong W, Daniels R, Demas A, Schaffner $\mathrm{S}$, Amaratunga $\mathrm{C}$, Lim $\mathrm{P}$, Dhorda $\mathrm{M}$, et al. Artemisinin resistance without pfkelch13 mutations in Plasmodium falciparum isolates from Cambodia. Malar J. 2017;16(1):195.

84. Rocamora F, Zhu L, Liong KY, Dondorp A, Miotto O, Mok S, Bozdech Z. Oxidative stress and protein damage responses mediate artemisinin resistance in malaria parasites. PLoS Path. 2018;14(3):e1006930.

85. Siddiqui FA, Cabrera M, Wang M, Brashear A, Kemirembe K, Wang Z, Miao J, Chookajorn T, Yang Z, Cao Y, et al. Plasmodium falciparum Falcipain-2a polymorphisms in Southeast Asia and their association with artemisinin resistance. J Infect Dis. 2018;218(3):434-42

86. Straimer J, Gnadig NF, Stokes BH, Ehrenberger M, Crane AA, Fidock DA. Plasmodium falciparum K13 mutations differentially impact ozonide susceptibility and parasite fitness in vitro. mBio. 2017;8(2):e00303-17.

87. Ikeda M, Kaneko M, Tachibana SI, Balikagala B, Sakurai-Yatsushiro M, Yatsushiro S, Takahashi N, Yamauchi M, Sekihara M, Hashimoto M, et al. Artemisinin-resistant Plasmodium falciparum with high survival rates, Uganda, 2014-2016. Emerg Infect Dis. 2018;24(4):718-26.

\section{Ready to submit your research? Choose BMC and benefit from:}

- fast, convenient online submission

- thorough peer review by experienced researchers in your field

- rapid publication on acceptance

- support for research data, including large and complex data types

- gold Open Access which fosters wider collaboration and increased citations

- maximum visibility for your research: over $100 \mathrm{M}$ website views per year

At BMC, research is always in progress.

Learn more biomedcentral.com/submissions 